\title{
Identification and Characterization of a Novel Large-Conductance Calcium-Activated Potassium Channel Activator, CTIBD, and Its Relaxation Effect on Urinary Bladder Smooth Muscle ${ }^{\mathrm{S}}$
}

\author{
Narasaem Lee, Bong Hee Lim, Kyu-Sung Lee, Jimin Shin, Haushabhau S. Pagire, \\ Suvarna H. Pagire, Jin Hee Ahn, Sung Won Lee, Tong Mook Kang, and DChul-Seung Park \\ School of Life Sciences, Center for Al-applied High Efficiency Drug Discovery and Integrated Institute of Biomedical Research \\ (N.L., C.-S.P.) and Department of Chemistry (H.S.P., S.H.P., J.H.A.), Gwangju Institute of Science and Technology (GIST), \\ Gwangju, South Korea; Department of Urology, Samsung Medical Center, Samsung Biomedical Research Institute, \\ Sungkyunkwan University School of Medicine, Seoul, South Korea (B.H.L., K.-S.L., J.S., S.W.L.); and Department of Physiology, \\ Sungkyunkwan University School of Medicine, Suwon, South Korea (T.M.K.)
}

Received June 30, 2020; accepted November 11, 2020

\begin{abstract}
The large-conductance calcium-activated potassium channel $\left(\mathrm{BK}_{\mathrm{Ca}}\right.$ channel) is expressed on various tissues and is involved in smooth muscle relaxation. The channel is highly expressed on urinary bladder smooth muscle cells and regulates the repolarization phase of the spontaneous action potentials that control muscle contraction. To discover novel chemical activators of the $\mathrm{BK}_{\mathrm{Ca}}$ channel, we screened a chemical library containing 8364 chemical compounds using a cell-based fluorescence assay. A chemical compound containing an isoxazolyl benzene skeleton (compound 1) was identified as a potent activator of the $\mathrm{BK}_{\mathrm{Ca}}$ channel and was structurally optimized through a structureactivity relationship study to obtain 4-(4-(4-chlorophenyl)-3(trifluoromethyl)isoxazol-5-yl)benzene-1,3-diol (CTIBD). When CTIBD was applied to the treated extracellular side of the channel, the conductance-voltage relationship of the channel shifted toward a negative value, and the maximum conductance increased in a concentration-dependent manner. CTIBD altered the gating kinetics of the channel by dramatically slowing channel
\end{abstract}

closing without effecting channel opening. The effects of CTIBD on bladder muscle relaxation and micturition function were tested in rat tissue and in vivo. CTIBD concentration-dependently reduced acetylcholine-induced contraction of urinary bladder smooth muscle strips. In an acetic acid-induced overactive bladder (OAB) model, intraperitoneal injection of $20 \mathrm{mg} / \mathrm{kg}$ CTIBD effectively restored frequent voiding contraction and lowered voiding volume without affecting other bladder function parameters. Thus, our results indicate that CTIBD and its derivatives are novel chemical activators of the bladder $\mathrm{BK}_{\mathrm{Ca}}$ channel and potential candidates for OAB therapeutics.

\section{SIGNIFICANCE STATEMENT}

The novel $\mathrm{BK}_{\mathrm{Ca}}$ channel activator CTIBD was identified and characterized in this study. CTIBD directly activates the $\mathrm{BK}_{\mathrm{Ca}}$ channel and relaxes urinary bladder smooth muscle of rat, so CTIBD can be a potential candidate for overactive bladder therapeutics.
This work was supported by the Korea Institute of Planning and Evaluation for Technology in Food, Agriculture, and Forestry (IPET) through the Agri-Bio Industry Technology Development Program; funded by the Ministry of Agriculture, Food and Rural Affairs (MAFRA) [317070-4]; and supported by a Gwangju Institute of Science and Technology (GIST) Research Institute (GRI) Integrated Institute of Biomedical Research (IIBR) grant funded in 2020. https://doi.org/10.1124/molpharm.120.000106.

[] This article has supplemental material available at molpharm. aspetjournals.org.

\section{Introduction}

The large-conductance calcium-activated potassium channel $\left(\mathrm{BK}_{\mathrm{Ca}}\right.$ channel; also called Maxi $\mathrm{K}$, Slo1, or $\left.\mathrm{K}_{\mathrm{Ca}} 1.1\right)$ is activated by membrane depolarization or increases in intracellular $\mathrm{Ca}^{2+}$ concentration (Barrett et al., 1982; Yang et al., 2015). Potassium ions pass through the channel rapidly from the intracellular side to the extracellular side when the $\mathrm{BK}_{\mathrm{Ca}}$ channel is opened, resulting in membrane hyperpolarization (Salkoff et al., 2006; Cui et al., 2009). The $\mathrm{BK}_{\mathrm{Ca}}$ channel is composed of four pore-forming $\alpha$ subunits and auxiliary $\beta$

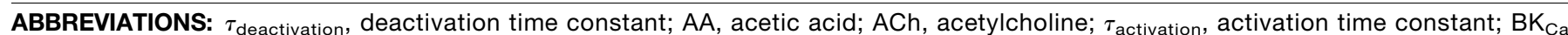
channel, large-conductance calcium-activated potassium channel; cRNA, complementary RNA; CTIBD, 4-(4-(4-chlorophenyl)-3-(trifluoromethyl)isoxazol-5-yl)benzene-1,3-diol; d, doublet peak; dd, doublet of doublet peak; EtOAc, ethyl acetate; $G_{\text {max }}$, maximum conductance; G-V, conductance-voltage; KRICT, Korea Research Institute of Chemical Technology; OAB, overactive bladder; r $\beta 1$, rat $\beta 1$ subunit; $r \beta 4$, rat $\beta 4$ subunit; RFU, relative fluorescence unit; rSlo, rat BKCa channel; s, singlet peak; SAR, structure-activity relationship; Slo1, a subunit of large-conductance calcium-activated potassium channel; UBSM, urinary bladder smooth muscle; $V_{1 / 2}$, half-activation voltage. 
subunits. Four types of $\beta$ subunits, $\beta 1-\beta 4$, show tissue-specific distributions and affect the activation of $\mathrm{BK}_{\mathrm{Ca}}$ channels (Orio et al., 2002). The $\mathrm{BK}_{\mathrm{Ca}}$ channel is expressed in the brain, smooth muscle, bladder, cochlea, and other various tissues (Poulsen et al., 2009). The $\mathrm{BK}_{\mathrm{Ca}}$ channel regulates several physiologic processes-for example, neurotransmitter release (Wang, 2008), smooth muscle contraction (Wu and Marx, 2010), hormone secretion from endocrine cells (Marty, 1981; Wang et al., 1994), hearing (Salkoff et al., 2006), and circadian rhythms (Meredith et al., 2006). Based on these roles, malfunction of the $\mathrm{BK}_{\mathrm{Ca}}$ channel is linked to several diseases, such as stroke (Gribkoff et al., 2001), erectile dysfunction (Werner et al., 2005), and overactive bladder (OAB) (Layne et al., 2010). In addition, a gain-of-function mutation of the $\mathrm{BK}_{\mathrm{Ca}}$ channel was linked to epilepsy and paroxysmal dyskinesia (Du et al., 2005).

OAB syndrome makes patients feel frequent urinary urgency both day and night (Cerruto et al., 2012). In the United States, $16.0 \%$ of men and $16.9 \%$ of women suffer from OAB (Stewart et al., 2003). In the urination pathway, acetylcholine $(\mathrm{ACh})$ released from parasympathetic nerves binds to muscarinic receptors on urinary bladder smooth muscle (UBSM) to induce contraction of UBSM and urination (Hegde and Eglen, 1999). Muscarinic receptor antagonists, which inhibit AChinduced UBSM contraction, are commonly used to treat OAB (Abrams and Andersson, 2007). However, these induce several side effects, such as blurred vision, dry mouth, constipation, tachycardia, and cognitive impairment (Eglen et al., 1999; Kay and Granville, 2005). Therefore, different therapeutic targets for $\mathrm{OAB}$ syndrome that are associated with fewer side effects need to be studied.

As mentioned previously, the $\mathrm{BK}_{\mathrm{Ca}}$ channel controls smooth muscle contraction (Wu and Marx, 2010). The $\mathrm{BK}_{\mathrm{Ca}}$ channel is highly expressed in UBSM cells (Hristov et al., 2011), where it maintains the resting membrane potential and regulates the repolarization phase of the spontaneous action potential that controls UBSM contraction (Petkov, 2014). Cholinergic- and purinergic-induced contractility is decreased by $\mathrm{BK}_{\mathrm{Ca}}$ channel activation, and alterations in $\mathrm{BK}_{\mathrm{Ca}}$ channel expression or function affect OAB symptoms (Werner et al., 2007; Sprossmann et al., 2009). Thus, UBSM relaxation can be induced by $\mathrm{BK}_{\mathrm{Ca}}$ channel activation, suggesting that the $\mathrm{BK}_{\mathrm{Ca}}$ channel is a potential therapeutic target for the treatment of $\mathrm{OAB}$.

In this study, we screened 8364 chemical compounds using a cell-based fluorescence assay to search for a novel $\mathrm{BK}_{\mathrm{Ca}}$ channel activator. $\mathrm{A} \mathrm{TI}^{+}$-based fluorescence assay platform, which measures the activity of voltage-gated $\mathrm{K}^{+}$channels, was used for screening the activity of the compounds against a mutant $\mathrm{BK}_{\mathrm{Ca}}$ channel. The channel has highly increased sensitivity to $\mathrm{Ca}^{2+}$, meaning an increase in intracellular $\mathrm{Ca}^{2+}$ concentration is not required for channel activation (Lee et al., 2013). From the initial screening and the secondary structureactivity relationship study, we identified one chemical compound, 4-(4-(4-chlorophenyl)-3-(trifluoromethyl)isoxazol-5-yl) benzene-1,3-diol (CTIBD), as a potent activator of the $\mathrm{BK}_{\mathrm{Ca}}$ channel. The conductance-voltage $(G-V)$ relationship of the $\mathrm{BK}_{\mathrm{Ca}}$ channel shifted to a more negative value in a concentration-dependent manner when CTIBD was applied to the extracellular side of the channel. In addition, CTIBD significantly decreased ACh-induced contraction of rat UBSM strips (Bo and Burnstock, 1990). When injected intraperitoneally into a rat model of acetic acid (AA)-induced OAB, CTIBD increased the reduced intercontraction interval and voiding volume significantly. Thus, CTIBD and its derivatives may hold potential as $\mathrm{OAB}$ therapeutics that target the $\mathrm{BK}_{\mathrm{Ca}}$ channel.

\section{Materials and Methods}

Materials. A chemical library, named the Korea Research Institute of Chemical Technology (KRICT) Diversity Library, which contains 8364 unique chemical compounds, was obtained from the KRICT (Daejeon, South Korea; www.chembank.org). CTIBD and other isoxazolyl benzene derivatives were first purchased from Vitas-M Laboratory (Causeway Bay, Hong Kong; www.vitasmlab. biz). After that, a large amount of CTIBD and its derivatives were synthesized (Supplemental Fig. 1). Those compounds are prepared by dissolving compounds in DMSO (Sigma-Aldrich, St. Louis, MO).

Synthesis of Compound 4 (CTIBD). Compound 4 (CTIBD) was synthesized as outlined in Scheme 1. The synthetic procedure is as follows for 2-(4-chlorophenyl)-1-(2,4-dihydroxyphenyl)ethan-1-one $\mathbf{3}$ : To a solution of resorcinol 1 (1.42 g, $12.89 \mathrm{mmol})$ in boron trifluoride diethyl etherate $(20 \mathrm{ml})$ was added 2-(4-chlorophenyl) acetic acid $2(2 \mathrm{~g}, 11.72 \mathrm{mmol})$, and the reaction mixture was heated at $75^{\circ} \mathrm{C}$ for 4 hours under a nitrogen atmosphere. The mixture was poured into water and extracted with ethyl acetate (EtOAc). The organic layer was separated, dried over anhydrous $\mathrm{Na}_{2} \mathrm{SO}_{4}$, filtered, and concentrated in vacuo. Purification of the resulting residue by column chromatography using EtOAc/hexane as the eluent provided 2-(4-chlorophenyl)-1-(2,4dihydroxyphenyl)ethan-1-one 3 (1.7 $\mathrm{g}, 55 \%$ yield). NMR data of 3 is as follows: ${ }^{1} \mathrm{H}$ NMR (DMSO- $\left.d_{6}\right) \delta 12.40(\mathrm{~s}, 1 \mathrm{H}), 10.69(\mathrm{~s}, 1 \mathrm{H}), 7.93(\mathrm{~d}, J=$ $8.85 \mathrm{~Hz}, 1 \mathrm{H}), 7.37(\mathrm{~d}, J=8.24 \mathrm{~Hz}, 2 \mathrm{H}), 7.30(\mathrm{~d}, J=8.54 \mathrm{~Hz}, 2 \mathrm{H}), 6.40$ (dd, $J=8.85,2.14 \mathrm{~Hz}, 1 \mathrm{H}), 6.26(\mathrm{~d}, J=2.44 \mathrm{~Hz}, 1 \mathrm{H}), 4.33(\mathrm{~s}, 2 \mathrm{H})$.

4-(4-(4-Chlorophenyl)-3-(trifluoromethyl)isoxazol-5-yl)benzene-1,3diol 4: To a solution of 2-(4-chlorophenyl)-1-(2,4-dihydroxyphenyl) ethan-1-one $3(1.7 \mathrm{~g}, 6.47 \mathrm{mmol})$ in pyridine $(5 \mathrm{ml})$, trifluoroacetic anhydride ( $2.8 \mathrm{ml}, 19.42 \mathrm{mmol}$ ) was added dropwise with cooling in an ice bath, and then the mixture was stirred at room temperature for 48 hours. The mixture was concentrated to dryness to yield 3-(4chlorophenyl)-7-hydroxy-2-(trifluoromethyl)-4H-chromen-4-one, which was used for the next step. A mixture of 3-(4-chlorophenyl)-7-hydroxy2-(trifluoromethyl)-4H-chromen-4-one and hydroxylamine hydrochloride $(856.7 \mathrm{mg}, 12.33 \mathrm{mmol})$ dissolved in pyridine was heated at reflux for 12 hours and then cooled to room temperature. The reaction

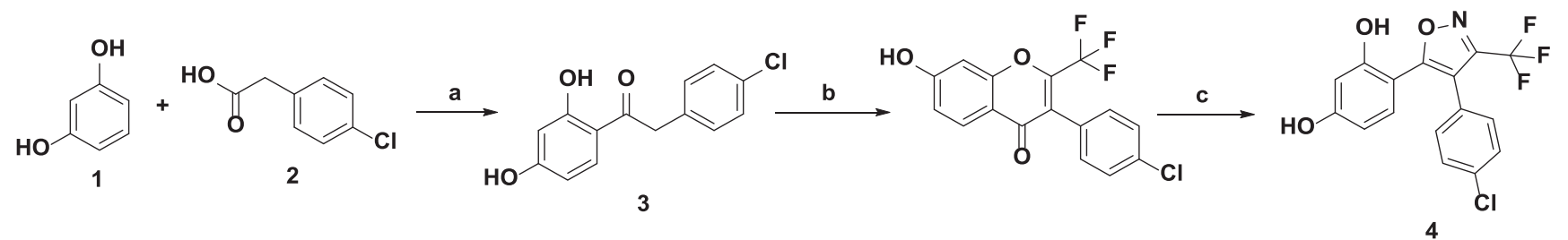

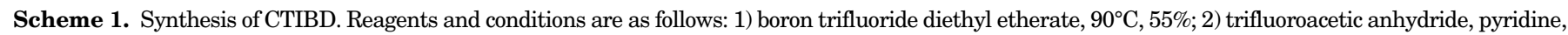
$0^{\circ} \mathrm{C}$ to room temperature, 48 hours (without isolation used for next step); 3 ) hydroxylamine hydrochloride, pyridine, reflux, 12 hours, $51 \%$ (over two steps). 
mixture was acidified with dilute $\mathrm{HCl}$ and extracted with EtOAc. The organic layer was separated and washed with saline solution, dried over anhydrous $\mathrm{Na}_{2} \mathrm{SO}_{4}$, and concentrated in vacuo. The resulting residue was purified by column chromatography to provide 4-(4-(4chlorophenyl)-3-(trifluoromethyl)isoxazol-5-yl)benzene-1,3-diol 4 (800 $\mathrm{mg}, 51 \%$ yield over two steps). Characterization of 4 is as follows: ${ }^{1} \mathrm{H}$ NMR (DMSO- $\left.d_{6}\right) \delta 9.96(\mathrm{~s}, 1 \mathrm{H}), 9.95(\mathrm{~s}, 1 \mathrm{H}), 7.52-7.42$ (multiplet peak, $2 \mathrm{H}), 7.28(\mathrm{~d}, J=8.24 \mathrm{~Hz}, 2 \mathrm{H}), 7.10(\mathrm{~d}, J=8.24 \mathrm{~Hz}, 1 \mathrm{H}), 6.33(\mathrm{~d}, J=2.14 \mathrm{~Hz}$, $1 \mathrm{H}), 6.28$ (dd, $J=8.54,2.14 \mathrm{~Hz}, 1 \mathrm{H}$ ); liquid chromatography-mass spectrometry (mass-to-charge ratio): $356.1(\mathrm{M}+\mathrm{H})$.

Fluorescence Assay and Data Analysis. Modified human embryonic kidney cells (AD-293 cells) that stably express a mutant $\mathrm{BK}_{\mathrm{Ca}}$ channel (G803D/N806K) (Lee et al., 2013) were used for the cellbased assay. Cells were grown in high-glucose Dulbecco's modified Eagle's medium (Hyclone, Logan, UT) containing 10\% fetal bovine serum (Hyclone) and $1 \mathrm{mg} / \mathrm{ml}$ geneticin (Gibco/Life Technologies, Waltham, MA). Approximately 20,000 cells per well were seeded on a 96-well clear-bottom black-wall assay plate (Corning Incorporated, Corning, NY) coated with poly(D-lysine) (Sigma-Aldrich). The cellbased assay used a FluxOR potassium channel assay kit (Invitrogen, Eugene, OR) and was performed using the following steps. First, cell growth medium was removed, and $80 \mu \mathrm{l}$ of loading buffer containing FluxOR fluorescent dye was added to each well. The plate was then incubated at room temperature in the dark for 1 hour. After incubation, loading buffer was removed, and $100 \mu \mathrm{l}$ of assay buffer containing varying concentrations of test compounds was added to each well of the plate. The plate was incubated at room temperature for 20-30 minutes. DMSO (1\%) was used as the vehicle. DMSO $1 \%$ did not affect fluorescence signal significantly. Fluorescence was measured using a FlexStation 3 multimode microplate reader (Molecular Devices, Sunnyvale, CA) and SoftMax Pro software. A hybrid multimode microplate reader (Synergy H1; BioTek Instrument Inc., Winooski, VT) and Gen5 software were used for Supplemental Data. The fluorescence excitation wavelength was $485 \mathrm{~nm}$, and the emission wavelength was $528 \mathrm{~nm}$. The fluorescence signal was measured every 2 seconds for FlexStation 3 and every 10 seconds for Synergy H1. Depolarization of the cell membrane was induced chemically by the addition of $20 \mu \mathrm{l}$ of stimulus buffer containing a high concentration of $\mathrm{TI}^{+}$to each well. For FlexStation 3, stimulus buffer is added automatically 20 seconds after initiation of fluorescence measurements. In the case of Synergy H1, stimulus buffer is added manually 40 seconds after initiation of fluorescence measurements. Fluorescence signals were analyzed as relative fluorescence units (RFU or $F$ / $F_{O}, F_{0}$ : minimum value of fluorescence signals of each well). One-way ANOVA was used for statistical analysis $\left({ }^{*} P\right.$ value $<0.05$, $* * P$ value $<$ $0.01, * * * P$ value $<0.001)$

Functional Expression of the $\mathrm{BK}_{\mathrm{Ca}}$ Channel in Xenopus Oocytes. Rat $\mathrm{BK}_{\mathrm{Ca}}$ channel $\alpha$ (Slo1), $\beta 1$, and $\beta 4$ subunits were expressed in Xenopus laevis oocytes for electrophysiological recording. An oocyte expression vector ( $\mathrm{pNBC} 1.0$ or pNBC2.0) was used for rat $\mathrm{BK}_{\mathrm{Ca}}$ channel subcloning and functional expression, which were carried out according to previously described methods (Ha et al., 2006). The cDNA sequence information is listed in GenBank. The accession number of the rat $\mathrm{BK}_{\mathrm{Ca}}$ channel $\alpha$ subunit was AF135265, the $\beta 1$ subunit was FJ154955.1, and the $\beta 4$ subunit was AY028605.

Oocytes were taken surgically from the ovarian lobes of $X$. laevis at stages V-VI (Nasco, Fort Atkinson, WI), placed in $\mathrm{Ca}^{2+}$-free oocyte Ringer's culture medium [ $86 \mathrm{mM} \mathrm{NaCl}, 1.5 \mathrm{mM} \mathrm{KCl}, 2 \mathrm{mM} \mathrm{MgCl}_{2}$, and $10 \mathrm{mM}$ HEPES ( $\mathrm{pH} 7.6$ )] containing $3 \mathrm{mg} / \mathrm{ml}$ collagenase (Worthington Biochemicals, Freehold, NJ), and incubated for 1.5-2 hours at room temperature to remove the follicular cell layer. After incubation,

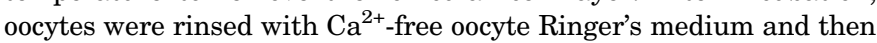
$\mathrm{ND}-96$ medium $\left[96 \mathrm{mM} \mathrm{NaCl}, 2 \mathrm{mM} \mathrm{KCl}, 1.8 \mathrm{mM} \mathrm{CaCl}_{2}, 1 \mathrm{mM} \mathrm{MgCl}_{2}\right.$, $5 \mathrm{mM}$ HEPES, and $50 \mathrm{~g} / \mathrm{ml}$ gentamicin (pH 7.6)]. Rinsed oocytes were incubated in ND-96 medium at $18^{\circ} \mathrm{C}$ for at least 24 hours to stabilize. Approximately $50 \mathrm{ng}$ of synthesized Slo1 cRNA prepared in nucleasefree water was injected into each oocyte, after which they were incubated at $18^{\circ} \mathrm{C}$ for $1-3$ days in ND-96 medium. For the coexpression experiments, cRNA of $\mathrm{r} \beta 1$ and $\mathrm{r} \beta 4$ subunits were injected into each oocyte with Slo1 cRNA. The molar ratio of $\beta$ subunit cRNA versus Slo1 cRNA was 12:1. That ratio guarantees sufficient coassembling of $\alpha$ and $\beta$ subunits of the $\mathrm{BK}_{\mathrm{Ca}}$ channel. The vitelline membrane was removed using fine forceps before electrophysiological recordings.

Electrophysiological Recordings and Data Analysis. A gigaohm seal patch-clamp method with membranes in an outside-out configuration was used for recording macroscopic currents, as described previously (Ha et al., 2006). Borosilicate glass pipettes (World Precision Instruments, Sarasota, FL) were pulled and fire-polished, and they had a resistance of 3-5 M $\Omega$. To facilitate electrophysiological recordings, the channel current was amplified using an Axopatch 200B amplifier (Molecular Devices, San Jose, CA) and low-passfiltered at $1 \mathrm{kHz}$ using a four-pole Bessel filter. The channel currents were digitized at a rate of 10 or 20 points per millisecond using a Digidata 1200A (Molecular Devices).

For the recording of currents, $\mathrm{BK}_{\mathrm{Ca}}$ channel currents were activated by voltage-clamp pulses from -80 to $200 \mathrm{mV}$ in $10-\mathrm{mV}$ increments. The resting potential was held at $-100 \mathrm{mV}$. Oocytes were placed in recording solution, which contained $120 \mathrm{mM}$ potassium gluconate, $10 \mathrm{mM}$ HEPES, $4 \mathrm{mM} \mathrm{KCl}$, and $5 \mathrm{mM}$ EGTA ( $\mathrm{pH} \mathrm{7.2).} \mathrm{The}$ MaxChelator program (Patton et al., 2004) was used to calculate the concentration of free $\mathrm{Ca}^{2+}$ in the intracellular solution. The intracellular solution contained $116 \mathrm{mM} \mathrm{KOH}, 10 \mathrm{mM}$ HEPES, and $4 \mathrm{mM} \mathrm{KCl}$ ( $\mathrm{pH} 7$ ). Concentrations of $\mathrm{N}$-(2-hydroxyethyl)ethylenediamine$\mathrm{N}, \mathrm{N}^{\prime}, \mathrm{N}^{\prime}$-triacetic acid, EGTA, and free $\mathrm{Ca}^{2+}$ are calculated by the MaxChelator program. Solution exchange was completed within 0.5 seconds. Clampex 8.0 and Origin 9.1 software (OriginLab Corporation, Northampton, MA) were used for data acquisition and analysis. Data were summarized as means \pm S.D. A two-tailed paired $t$ test was used for statistical analysis $(* P$ value $<0.05$; ** $P$ value $<0.01$; $* * * P$ value $<0.001)$

Isometric Tension Recording from UBSM. Experiments recording the isometric tension of UBSM were performed according to a previously described method (Lee et al., 2016). Briefly, bladder strips were isolated from male Sprague-Dawley rats $(300-350 \mathrm{~g})$. The isolated strips (approximately $2 \times 8 \mathrm{~mm}$ ) were mounted in $10-\mathrm{ml}$ organ baths containing Krebs' solution [118.4 mM NaCl, $4.7 \mathrm{mM} \mathrm{KCl}$, $1.2 \mathrm{mM} \mathrm{KH}_{2} \mathrm{PO}_{4}, 1.2 \mathrm{mM} \mathrm{MgSO}_{4}, 25.0 \mathrm{mM} \mathrm{NaHCO}, 2.5 \mathrm{mM} \mathrm{CaCl}_{2}$, and $12.2 \mathrm{mM}$ glucose $(\mathrm{pH} 7.4)$, bubbled with a mixture $95 \% \mathrm{O}_{2}$ and $5 \% \mathrm{CO}_{2}$ at $37^{\circ} \mathrm{C}$ ]. Isometric force measurements were recorded using a Power Laboratory Data Acquisition System (ADInstruments, Australia, NSW) attached to a computer installed with LabChart software (version 7; ADInstruments). Before each experiment, bladder strips were subjected to $1 \mathrm{~g}$ of resting tension and allowed to equilibrate for at least 1 hour. After this equilibration period, each strip was repeatedly exposed to $10 \mu \mathrm{M}$ ACh until constant responses were recorded with a washout period of 30 minutes. The strips were then pretreated for 30 minutes with CTIBD or $0.1 \%$ DMSO, and then $\mathrm{ACh}$-induced contractile responses were measured in the presence of CTIBD or DMSO. The relaxant response to CTIBD was expressed as the percent decrease in the ACh-induced contractile tension in the presence of CTIBD. One-way ANOVA was used for statistical analysis $(* P$ value $<0.05 ; * * P$ value $<0.01 ; * * * P$ value $<0.001)$

In Vivo Cystometry. Adult female Sprague-Dawley rats weighing $296 \pm 15 \mathrm{~g}$ (approximately 13 to 14 weeks old) were anesthetized with isoflurane $(3 \%, 3 \mathrm{ml} / \mathrm{min})$, and a polyethylene catheter (PE-50) was implanted into the bladder. Cystometry was performed 3 days after catheter insertion under anesthesia (urethane $1.3 \mathrm{~g} / \mathrm{kg}$, s.c.). The anesthetized animal was fixed supine on a vertically positioned table so that the urethra meatus of the animal pointed downward. A plastic cup placed underneath the urethra meatus and connected to a force transducer for weight measurement (FT0314618; Natus) was used to measure voided urine. The temperature of each animal was maintained at $37^{\circ} \mathrm{C}$ during anesthesia using a heating pad. In all experiments, the bladder was first filled with saline and then infused with saline for 1 hour at room temperature at a rate of $0.05 \mathrm{ml} / \mathrm{min}$. 
A

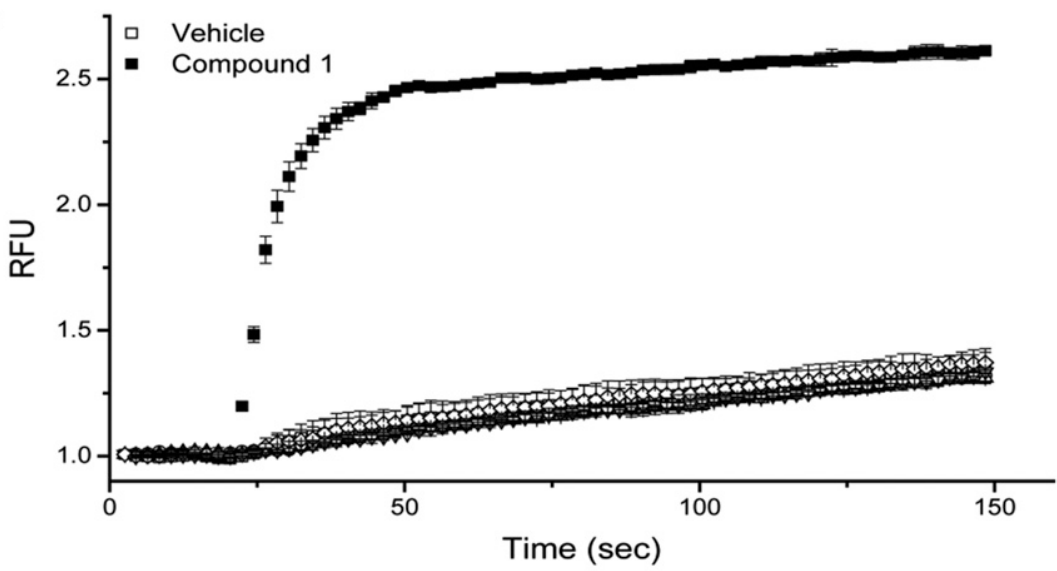

B

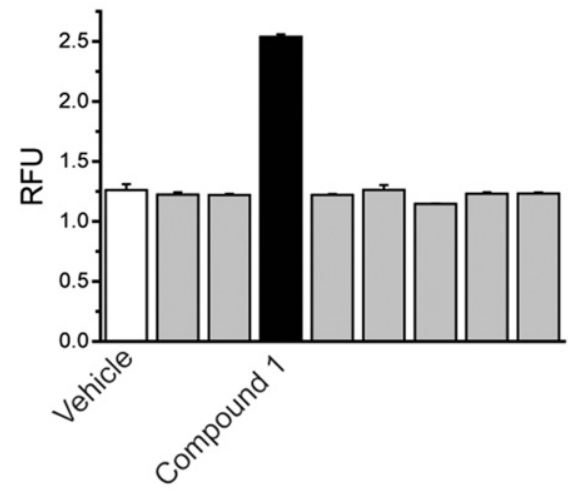

C

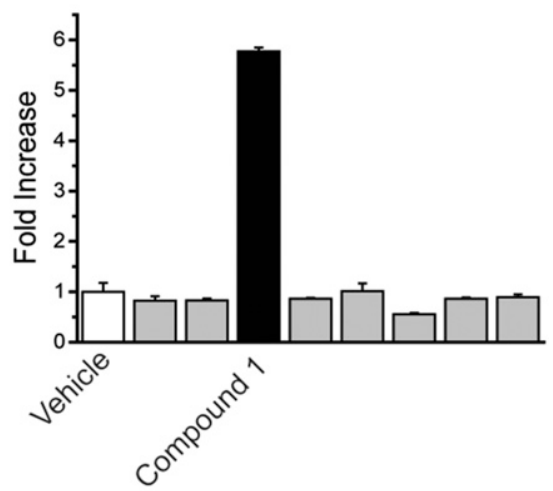

Fig. 1. Screening of a chemical library using a cell-based fluorescence assay. A chemical library of 8364 compounds (KRICT Diversity Library) was screened to identify novel $\mathrm{BK}_{\mathrm{Ca}}$ channel activators. A hyperactive mutant $\mathrm{BK}_{\mathrm{Ca}}$ channel (G803D/N806K) expressed in AD-293 cells was used for the fluorescence assay. (A) Representative fluorescence traces of eight different compounds and vehicle (1\% DMSO) are shown. Each compound was added to each well at a final concentration of $5 \mu \mathrm{M}$ before the fluorescence signal was measured. At 20 seconds, stimulus buffer was added. Empty squares indicate vehicle ( $\square, 1 \%$ DMSO), and filled squares indicate compound $1(\mathbf{\square})$. The RFU value (B) and fold increase in RFU normalized to vehicle $(\mathrm{C})$ of eight compounds and vehicle are shown. The RFU value and fold increase were measured at 100 seconds. The black bar indicates compound 1 . Each error bar indicates S.D. $(n=3)$.
Then, $0.5 \%$ AA was infused to the same rat until a voiding contraction occurred or for a maximum duration of 20 minutes, whichever happened first. CTIBD was administered intraperitoneally to the same rat at a single dose of $20 \mathrm{mg} / \mathrm{kg} 40$ minutes after AA administration. Intravesical pressure was recorded for 90 minutes after AA administration. Baseline pressure (millimeters of mercury) in the bladder, maximum pressure of voiding contraction (millimeters of mercury), intercontraction interval (seconds), and voiding volume (milliliters) were averaged for a 30- to 90-minute period postadministration in each animal. Normal saline filling, 0.5\% AA infusing, and intraperitoneal injection of CTIBD were continuously performed in the same rat. Voiding volume was measured accumulatively during the experiment. One-way ANOVA was used for statistical analysis ( $* P$ value $<0.05$; ** $P$ value $<0.01 ; * * * P$ value $<0.001)$.

Animal Use Approval. This study was reviewed and approved by the Institutional Animal Care and Use Committee of Samsung Medical Center. Samsung Medical Center is a facility accredited by the Association for Assessment and Accreditation of Laboratory Animal Care International and abides by the Institute of Laboratory Animal Resources guide.

\section{Results}

Identifying $\mathrm{BK}_{\mathrm{Ca}}$ Channel Activators Using a Cell-Based Fluorescence Assay. A chemical library containing 8364 chemical compounds was screened using a cell-based fluorescence assay to identify novel $\mathrm{BK}_{\mathrm{Ca}}$ channel activators. One compound (compound 1, at $5 \mu \mathrm{M}$ ) increased the fluorescence signal by almost 6 -fold within 100 seconds compared with vehicle (1\% DMSO) (Fig. 1A). Since compound 1 was identified as 4-(4-phenyl)-3-(trifluoromethyl)isoxazol-5-yl)benzene1,3-diol, we purchased other derivatives containing a 4-phenylisoxazol-5-yl benzene skeleton and tested their effects on the $\mathrm{BK}_{\mathrm{Ca}}$ channel using the cell-based fluorescence assay. Among 19 additional compounds tested at $5 \mu \mathrm{M}$, eight compounds significantly increased fluorescence at 100 seconds (Supplemental Fig. 2), with compound 4 (or CTIBD) evoking the highest fluorescence (Fig. 2B; Supplemental Fig. 2). At $5 \mu \mathrm{M}$, CTIBD-induced fluorescence was 7.9-fold higher than vehicle-induced fluorescence (Fig. $2 \mathrm{C}$ ). The increase in fluorescence induced by CTIBD was concentration-dependent and blocked completely by $1 \mu \mathrm{M}$ paxilline (Fig. 3A), a selective blocker of the $\mathrm{BK}_{\mathrm{Ca}}$ channel (Sanchez and McManus, 1996). At $10 \mu \mathrm{M}$, CTIBD showed significantly higher levels of fluorescence compared with three other known $\mathrm{BK}_{\mathrm{Ca}}$ activators: NS 1619, NS 11021, and rottlerin (Supplemental Fig. 4).

Effects of CTIBD on the Macroscopic Currents of the $\mathbf{B K}_{\mathbf{C a}}$ Channel. To validate the cell-based assay results, we determined the effects of CTIBD on the $\mathrm{BK}_{\mathrm{Ca}}$ channel using electrophysiology. The $\alpha$ subunit of the wild-type rat $\mathrm{BK}_{\mathrm{Ca}}$ channel was expressed in Xenopus oocytes, and the macroscopic current of excised oocyte membranes was measured. The excised membrane configuration was outside-out, and the intracellular $\mathrm{Ca}^{2+}$ concentration was fixed at $3 \mu \mathrm{M}$. CTIBD was applied to the extracellular side of the excised membrane at $3 \mu \mathrm{M}, 30$ seconds after initiation of current measurements (Fig. 4). CTIBD increased the amplitude of macroscopic currents in a time-dependent manner (Fig. 4, b and c) from basal level (Fig. 4a). After removal of CTIBD, the channel 
A<smiles>Oc1ccc(-c2onc(C(F)(F)F)c2-c2ccccc2)c(O)c1</smiles>

Compound 1<smiles>CCOc1ccc(-c2onc(C(F)(F)F)c2-c2ccccc2)c(O)c1</smiles>

Compound 2<smiles>COc1ccc(-c2onc(C(F)(F)F)c2-c2ccc(Cl)cc2)c(O)c1</smiles>

Compound 3<smiles>COc1ccc(-c2onc(C(F)(F)F)c2-c2ccc(Br)cc2)c(O)c1</smiles>

Compound 6<smiles>COc1ccc(-c2c(C(F)(F)F)noc2-c2ccc(O)cc2O)cc1</smiles>

Compound 7<smiles>COc1ccc(C(C2CCC(OC)CC2)C(C2CCCC2O)C(F)(F)F)cc1</smiles>

Compound 8<smiles>Oc1ccc(-c2onc(C(F)(F)F)c2-c2ccc(Cl)cc2)c(O)c1</smiles>

Compound 4 (CTIBD)

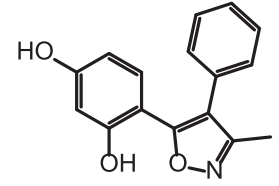

Compound 9<smiles>CCOc1ccc(C(c2noc(C(F)(F)F)c2C2CCC(Cl)CC2)C2CCCC2)c(O)c1</smiles>

Compound 5<smiles>COc1ccc(-c2onc(C(F)(F)F)c2-c2ccccc2)c(O)c1</smiles>

Compound 10
B

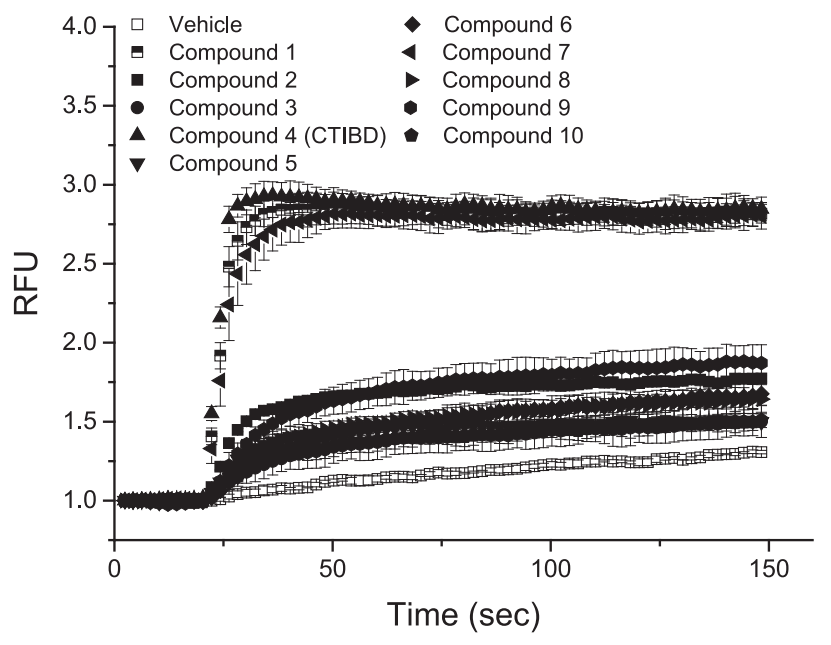

C

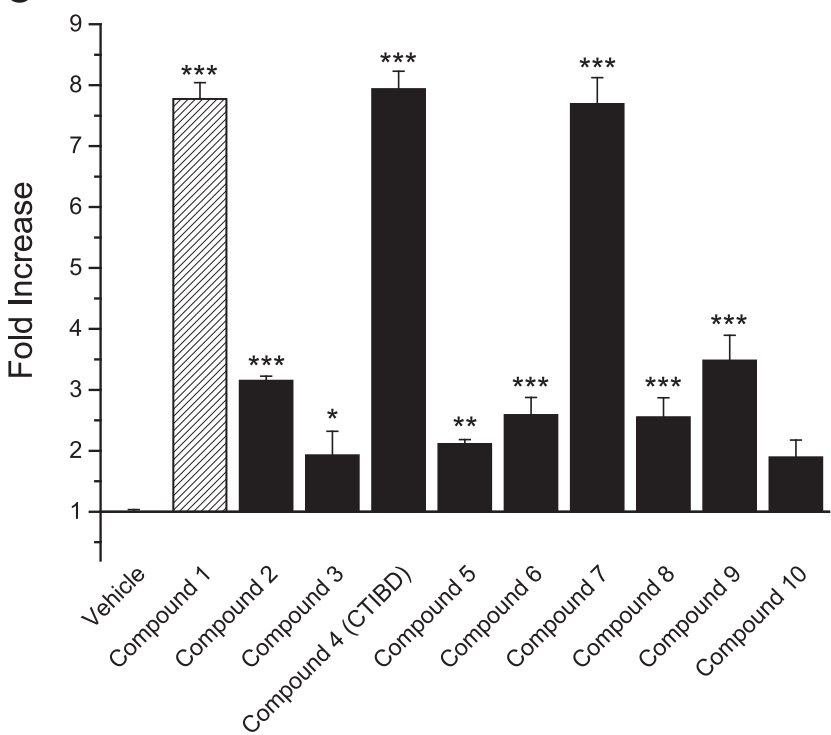

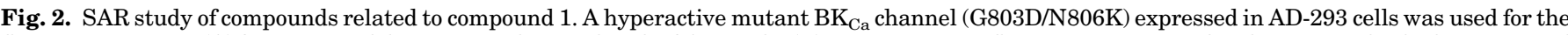

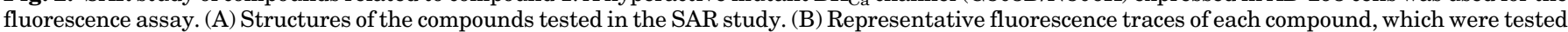

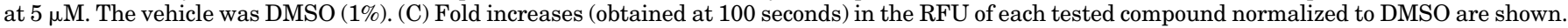

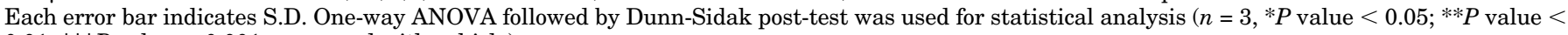
$0.01 ; * * * P$ value $<0.001$; compared with vehicle)

currents decreased almost completely to the basal level (Fig. 4d). CTIBD appeared to mediate the potentiation and depotentiation process of the $\mathrm{BK}_{\mathrm{Ca}}$ channel in two phases. During the potentiation process, for example, the channel current increased rapidly within a few seconds and then increased more steadily and gradually over a few minutes. Thus, the current data were fitted with a double-exponential function, and the time constants were estimated as $5.1 \pm 2.6$ and $48.3 \pm 8.8$ seconds for association and $4.3 \pm 3.1$ and $76.1 \pm$ 32.0 seconds for dissociation.

We then investigated the mechanism of CTIBD-induced $\mathrm{BK}_{\mathrm{Ca}}$ channel potentiation. A series of voltage pulses were applied to activate the $\mathrm{BK}_{\mathrm{Ca}}$ channel, and macroscopic currents were measured under different concentrations of CTIBD. When the extracellular concentration of CTIBD was increased, the channel was activated at a lower voltage, and the tail currents evoked by repolarization were drastically increased (Fig. 5A). Figure 5B represents the $G$ - $V$ relationship of $\mathrm{BK}_{\mathrm{Ca}}$ channel macroscopic currents under varying concentrations of CTIBD. Application of CTIBD shifted the $G$ - $V$ curve to a more negative voltage and increased the maximum conductance $\left(G_{\max }\right)$ in a concentration-dependent manner. The concentration-dependent shift of the $G-V$ relationship was quantified in terms of half-activation voltage $\left(V_{1 / 2}\right)$ (shown in Fig. 5C). As the extracellular concentration of CTIBD was increased from 0.1 to $10 \mu \mathrm{M}, V_{1 / 2}$ decreased by approximately $50 \mathrm{mV}$ from $155.8 \pm 5.8$ to $105.7 \pm 4.4 \mathrm{mV}$. These results indicate that CTIBD lowers the threshold voltage for activation and increases the maximum open probability of the $\mathrm{BK}_{\mathrm{Ca}}$ channel. A large negative shift of the $G-V$ relationship by CTIBD was also observed at a basal intracellular $\mathrm{Ca}^{2+}$ concentration of $0.1 \mu \mathrm{M}$ (Supplemental Fig. 5).

Effects of CTIBD on Gating Kinetics of the $\mathrm{BK}_{\mathrm{Ca}}$ Channel. Since the tail currents of the $\mathrm{BK}_{\mathrm{Ca}}$ channel were increased by CTIBD (Fig. 5A), we further investigated the effects of this compound on gating kinetics. Figure 6 shows 


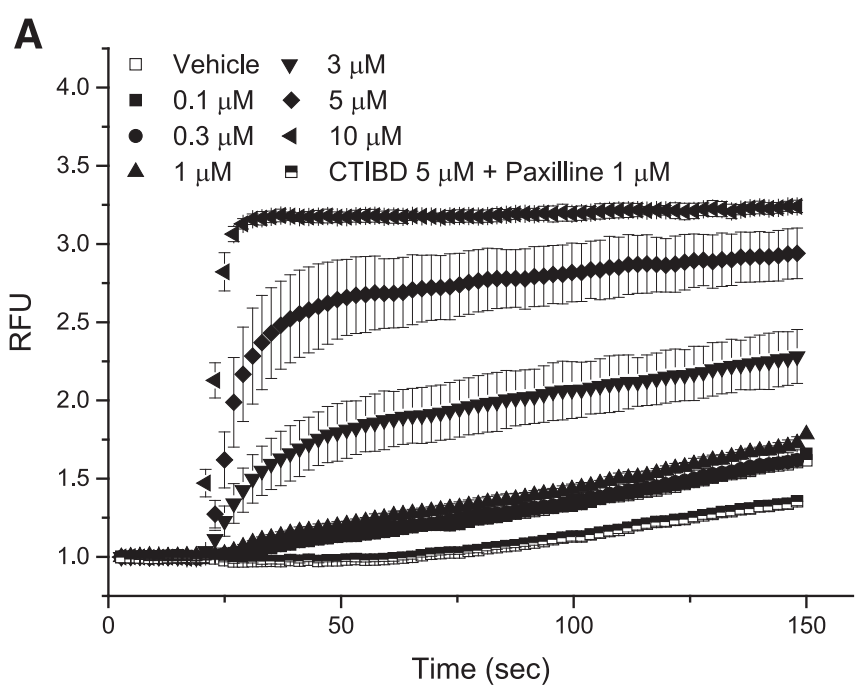

B

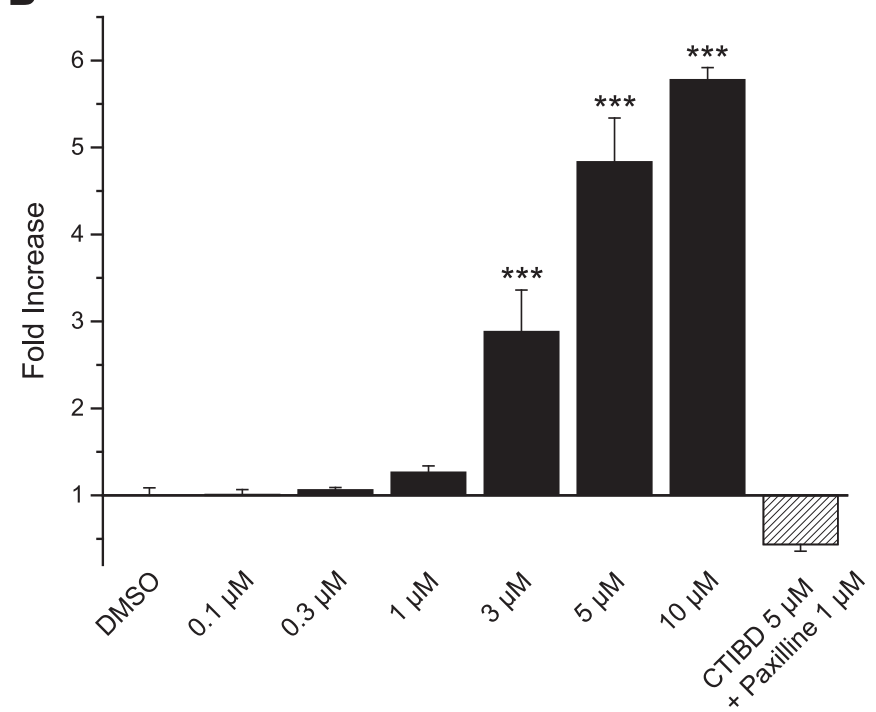

Fig. 3. CTIBD concentration-dependently increased fluorescence signals. The activity of various concentrations of CTIBD $[0.1 \mu \mathrm{M}(\boldsymbol{\square}), 0.3 \mu \mathrm{M}(\bullet), 1$ $\mu \mathrm{M}(\boldsymbol{\Delta}), 3 \mu \mathrm{M}(\boldsymbol{\nabla}), 5 \mu \mathrm{M}(\bullet), 10 \mu \mathrm{M}(\bullet)]$ and vehicle ( $\square, 1 \%$ DMSO) was tested on a hyperactive mutant $\mathrm{BK}_{\mathrm{Ca}}$ channel expressed in $\mathrm{AD}-293$ cells. (A) Representative fluorescence traces are shown. Cells were treated with CTIBD prior to fluorescence measurements, and stimulus buffer was added at 20 seconds. In some wells, $5 \mu \mathrm{M}$ CTIBD and $1 \mu \mathrm{M}$ paxilline $(\square)$ were added simultaneously. (B) Fold increase in RFU normalized to vehicle (1\% DMSO) induced by different concentrations of CTIBD. The empty bar is vehicle, black bars are different concentrations of CTIBD, and the striped bar is $5 \mu \mathrm{M}$ CTIBD and $1 \mu \mathrm{M}$ paxilline. Each error bar indicates S.D. One-way ANOVA followed by Dunn-Sidak post-test was used for statistical analysis $\left(n=4,{ }^{*} P\right.$ value $<0.05 ; * * P$ value $<0.01 ; * * * P$ value $<$ 0.001 , compared with vehicle).

the activation and deactivation kinetics of the $\mathrm{BK}_{\mathrm{Ca}}$ channel when analyzed in the absence and presence of $10 \mu \mathrm{M}$ CTIBD. Figure 6, A and B shows representative current traces of activation (or opening) and deactivation (or closing), respectively, of the $\mathrm{BK}_{\mathrm{Ca}}$ channel in the presence of $10 \mu \mathrm{M}$ compound. The activation time constant $\left(\tau_{\text {activation }}\right)$ values were obtained by fitting the current traces using a singleexponential function at each voltage (Fig. 6C). In the presence of $10 \mu \mathrm{M}$ CTIBD, the activation rate was slightly increased at all voltages tested. The effects of CTIBD on channel deactivation were dramatic, and the deactivation time constant
( $\left.\tau_{\text {deactivation }}\right)$ greatly increased (Fig. 6D). Channel closing greatly slowed in the presence of $10 \mu \mathrm{M}$ CTIBD at all voltages tested. The deactivation rate decreased by 11.5 -fold at $160 \mathrm{mV}$ in the presence of $10 \mu \mathrm{M}$ CTIBD. These results indicate that CTIBD potentiates $\mathrm{BK}_{\mathrm{Ca}}$ channel activity by slowing channel closing with minimal effects on channel opening and suggest that upon binding to the channel, the compound stabilizes the activation conformation of the $\mathrm{BK}_{\mathrm{Ca}}$ channel.

Effects of $\beta$ Subunits on CTIBD-Induced Activation of the $\mathbf{B K}_{\mathbf{C a}}$ Channel. Functional characteristics of the $\mathrm{BK}_{\mathrm{Ca}}$ channel are altered by auxiliary $\beta$ subunits. The effects of channel modulators can also be affected by the presence of $\beta$ subunits. In Figs. 7 and 8, the effect of $\beta$ subunits on CTIBDinduced potentiation of the $\mathrm{BK}_{\mathrm{Ca}}$ channel was examined. cRNA of rSlo and rat $\beta$ subunits were injected together to express $\mathrm{rSlo} / \mathrm{r} \beta 1$ or $\mathrm{rSlo} / \mathrm{r} \beta 4$ heteromeric $\mathrm{BK}_{\mathrm{Ca}}$ channels. Vehicle $(0.1 \%$ DMSO) or $10 \mu \mathrm{M}$ CTIBD was treated to the extracellular side of the membrane. At $10 \mu \mathrm{M}$ CTIBD, the $\mathrm{rSlo} / \mathrm{r} \beta 1$ channel shows a slight but significant shift of the $G-V$ relationship. $V_{1 / 2}$ values of vehicle-treated channel and $10 \mu \mathrm{M}$ CTIBD-treated channel were $114.9 \pm 6.7$ and $98.1 \pm 8.1 \mathrm{mV}$, respectively (Fig. 7B). In the case of the $\mathrm{rSlo} / \mathrm{r} \beta 4$ channel, the $V_{1 / 2}$ value was decreased approximately $40 \mathrm{mV}$ from $163.5 \pm$ 13.9 to $121.5 \pm 8.4 \mathrm{mV}$ at $10 \mu \mathrm{M}$ CTIBD (Fig. $8 \mathrm{~B}$ ).

Activation and deactivation time constant are also analyzed in Figs. 7 and 8. The activation time constant of the $\mathrm{rSlo} / \mathrm{r} \beta 1$ coexpressed $\mathrm{BK}_{\mathrm{Ca}}$ channel was slightly increased by CTIBD but did not show a significant difference compared with the vehicle-treated condition (Fig. 7C). On the other hand, the deactivation time constant of the $\mathrm{rSlo} / \mathrm{r} \beta 1$ coexpressed $\mathrm{BK}_{\mathrm{Ca}}$ channel was increased by CTIBD significantly (Fig. 7D). In the case of the $\mathrm{rSlo} / \mathrm{r} \beta 4$ coexpressed $\mathrm{BK}_{\mathrm{Ca}}$ channel, the activation time constant was slightly decreased by CTIBD, but it was only significant at low-voltage pulses between 150 and $170 \mathrm{mV}$ (Fig. 8C). The deactivation time constant of the $\mathrm{rSlo} / \mathrm{r} \beta 4$ coexpressed $\mathrm{BK}_{\mathrm{Ca}}$ channel was dramatically increased by

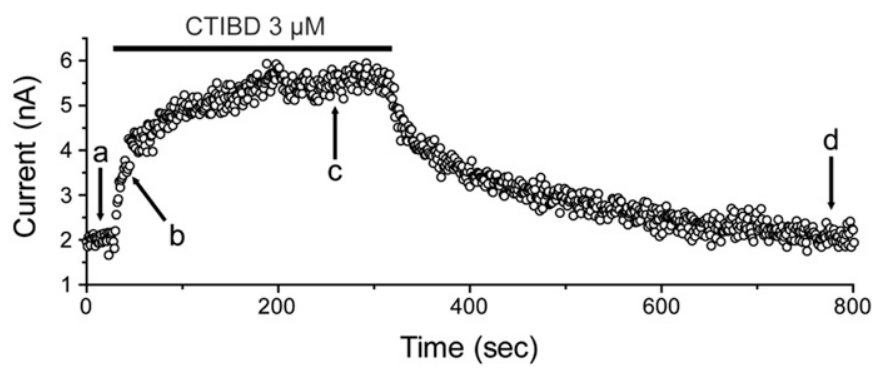

a

b

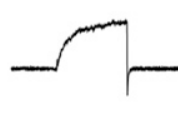

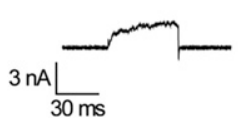

C

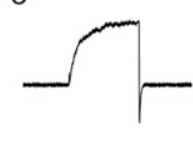

d
Fig. 4. CTIBD induced a reversible potentiation of macroscopic outward currents of the $\mathrm{BK}_{\mathrm{Ca}}$ channel. A representative plot of the $\mathrm{BK}_{\mathrm{Ca}}$ channel outward currents is shown. $\mathrm{BK}_{\mathrm{Ca}}$ channel was activated once every second by a $100-\mathrm{mV}$ pulse. The duration of each voltage pulse was 50 milliseconds, and the holding voltage was $-100 \mathrm{mV}$. Macroscopic currents of the $\mathrm{BK}_{\mathrm{Ca}}$ channel were recorded once every second. Dots on the representative plot indicate the mean value of the outward current. After initiation of $100-\mathrm{mV}$ pulses, mean currents were obtained from outward current values between 20 and 40 milliseconds. Representative current traces (a-d) show current traces of arrow-pointed spots. 
A

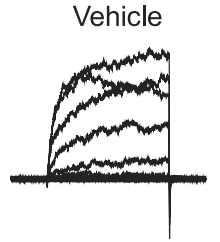

Vehicle

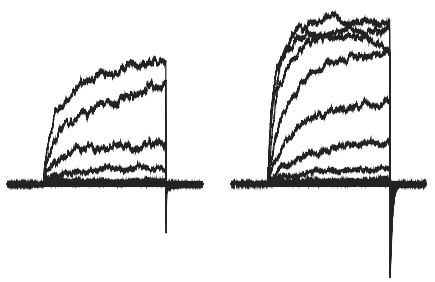

B

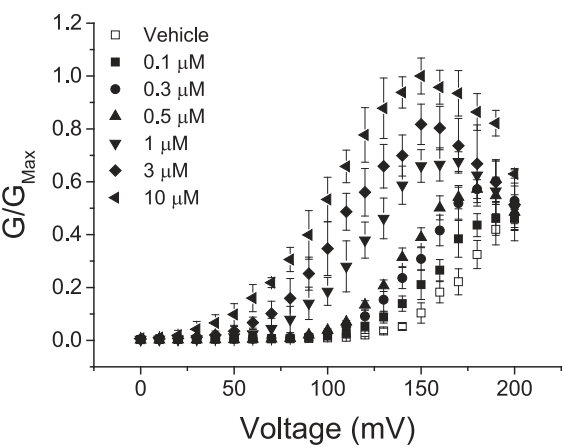

$0.1 \mu \mathrm{M}$ CTIBD

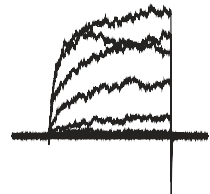

$3 \mu \mathrm{M}$ CTIBD
C

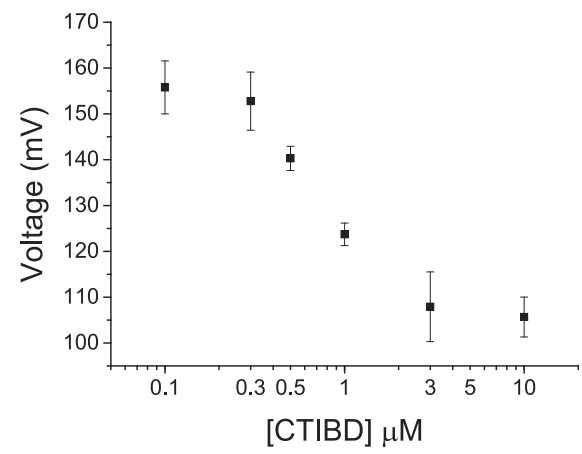

Fig. 5. Effects of CTIBD on the conductancevoltage relationship and $V_{1 / 2}$. (A) Representative current traces of the $\mathrm{BK}_{\mathrm{Ca}}$ channel. Intracellular $\mathrm{Ca}^{2+}$ concentration was $3 \mu \mathrm{M}$. The vehicle was DMSO $(0.1 \%)$. Various concentrations of CTIBD were applied to the extracellular side of the channel. The duration of the voltage pulses was 100 milliseconds. Currents were recorded at every voltage pulse, which were increased from -80 to $200 \mathrm{mV}$ in $10-\mathrm{mV}$ increments. The holding voltage was $-100 \mathrm{mV}$. Representative current traces at every $20 \mathrm{mV}$ from -80 to $200 \mathrm{mV}$ are shown. (B) Effects of CTIBD on the conductancevoltage relationship of the $\mathrm{BK}_{\mathrm{Ca}}$ channel. Intracellular $\mathrm{Ca}^{2+}$ concentration was $3 \mu \mathrm{M}$. After initiation of voltage pulses, mean conductances were obtained from outward current values obtained between 40 and 60 milliseconds. All currents were normalized to the maximum current obtained with $10 \mu \mathrm{M}$ CTIBD. Vehicle ( $\square$, $0.1 \%$ DMSO, $n=6)$ and $0.1 \mu \mathrm{M}(\mathbf{\square}, n=6), 0.3 \mu \mathrm{M}$ $(\bullet, n=5), 0.5 \mu \mathrm{M}(\boldsymbol{\Lambda}, n=4), 1 \mu \mathrm{M}(\mathbf{\nabla}, n=4), 3 \mu \mathrm{M}$ $(\bullet, n=4)$, or $10 \mu \mathrm{M}(\langle, n=4)$ of CTIBD were applied to the extracellular side of the channel. (C) Effects of CTIBD on $V_{1 / 2}$. To obtain $V_{1 / 2}$, each current trace was individually fitted using the Boltzmann function $G / G_{\max }=\left\{\left(G_{\max }-G_{\min }\right) /(1+\right.$ $\left.\left.\exp \left[\left(V_{1 / 2}-V\right) / k\right]\right)\right\}+G_{\min }$, where $G=$ conductance. Each error bar indicates S.D.
CTIBD (Fig. 8D). The deactivation rate decreased by 7.6 -fold at $150 \mathrm{mV}$ in the presence of $10 \mu \mathrm{M}$ CTIBD. These results indicate that CTIBD activates both $\mathrm{rSlo} / \mathrm{r} \beta 1$ and $\mathrm{rSlo} / \mathrm{r} \beta 4$ coexpressed channels mainly by decreasing the closing rate of the channel, which is similar to the rSlo homomeric channel but occurs to a much lesser extent.

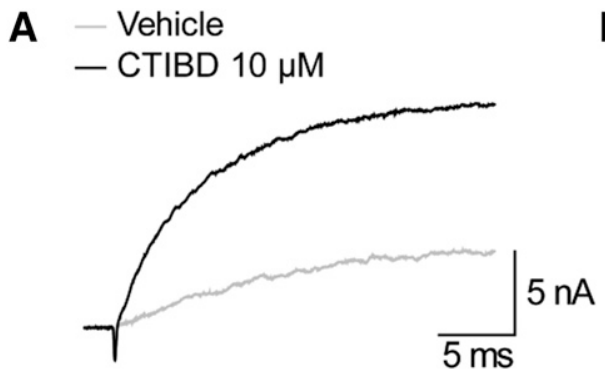

B

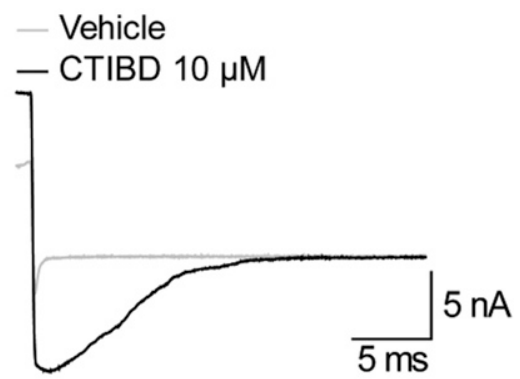

D

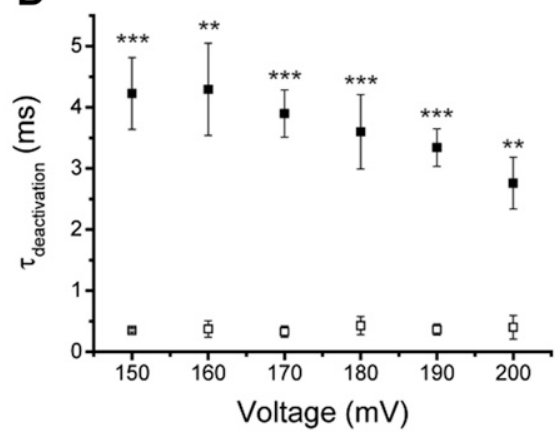

Fig. 6. Effects of CTIBD on the activation and deactivation of the $\mathrm{BK}_{\mathrm{Ca}}$ channel. Representative current traces of activation (A) and deactivation (B) are shown. Vehicle (0.1\% DMSO, gray lines) and $10 \mu \mathrm{M}$ CTIBD (black) were added to the extracellular side of the channel. All current traces were obtained at $150 \mathrm{mV}$. (C) $\tau_{\text {activation }}$ of the vehicle-treated $(\square, 0.1 \% \mathrm{DMSO}, n=4)$ and 10 $\mu \mathrm{M}$ CTIBD-treated $(\mathbf{\square}, n=4) \mathrm{BK}_{\mathrm{Ca}}$ channel. (D) $\tau_{\text {deactivation }}$ of the vehicle-treated $(\square, 0.1 \%$ DMSO, $n=4)$ and $10 \mu \mathrm{M}$ CTIBD-treated $(\boldsymbol{\square}, n=4) \mathrm{BK}_{\mathrm{Ca}}$ channel. Each error bar indicates S.D. To obtain time-constant values, all current traces were fitted individually with the exponential standard function $\left[y(t)=A_{1} \exp \left(-t / \tau_{1}\right)+C\right]$ in the Clampfit program. Two-tailed paired $t$ test was used for statistical analysis $(* P$ value $<0.05 ; * * P$ value $<$ $0.01 ; * * * P$ value $<0.001)$ 
A
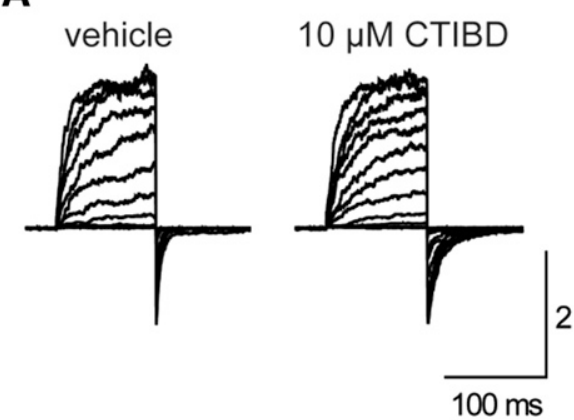

C

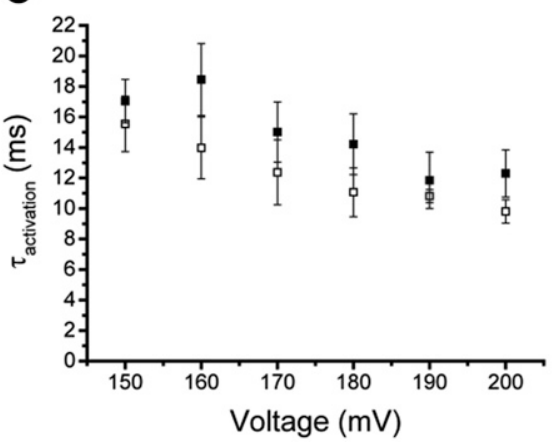

B

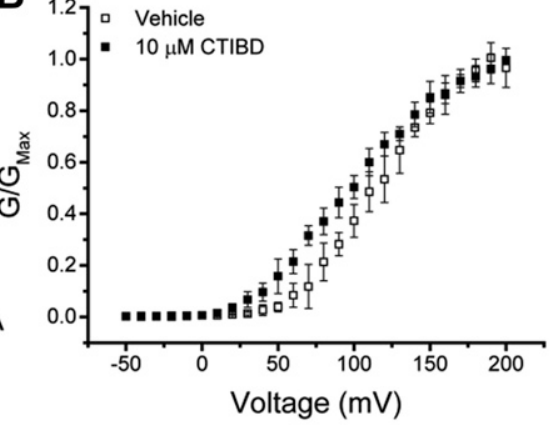

D

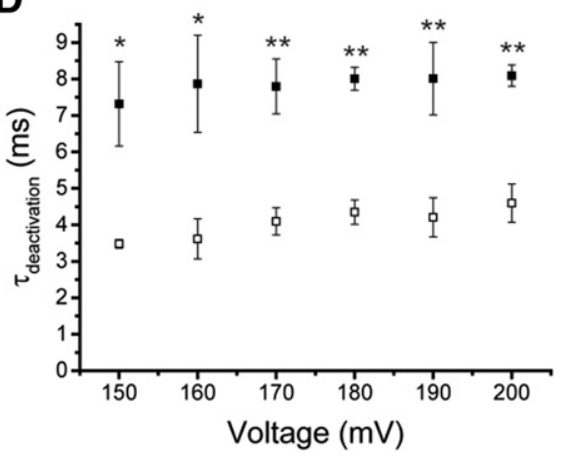

Fig. 7. Effects of $\beta 1$ subunits on CTIBD-induced activation of $\mathrm{BK}_{\mathrm{Ca}}$ channel. Intracellular $\mathrm{Ca}^{2+}$ concentration was $3 \mu \mathrm{M}$. (A) Representative current traces of $\mathrm{rSlo} / \mathrm{r} \beta 1$ coexpression channel. The vehicle was DMSO $(0.1 \%)$. CTIBD $(10 \mu \mathrm{m})$ was applied to the extracellular side of the channel. The duration of the voltage pulses was 100 milliseconds. Currents were recorded at every voltage pulse, which were increased from -80 to $200 \mathrm{mV}$ in $10-\mathrm{mV}$ increments. The holding voltage was $-100 \mathrm{mV}$. Representative current traces at every $20 \mathrm{mV}$ from -80 to $200 \mathrm{mV}$ are shown. (B) Effects of CTIBD on the conductancevoltage relationship of $\mathrm{rSlo} / \mathrm{r} \beta 1$ coexpression channel. After initiation of voltage pulses, mean conductances were obtained from outward current values obtained between 40 and 60 milliseconds. All currents were normalized to the maximum current obtained with $10 \mu \mathrm{M}$ CTIBD. Vehicle $(\square, 0.1 \%$ DMSO, $n=3)$ and $10 \mu \mathrm{M}(\boldsymbol{\square}, n=$ 3) CTIBD were applied to the extracellular side of the channel. (C) $\tau_{\text {activation }}$ of the vehicle-treated $(\square, 0.1 \%$ DMSO, $n=3$ ) and $10 \mu \mathrm{M}$ CTIBDtreated $(\boldsymbol{\square}, n=3) \mathrm{rSlo} / \mathrm{r} \beta 1$ coexpression channel. (D) $\tau_{\text {deactivation }}$ of the vehicle-treated $(\square, 0.1 \% \mathrm{DMSO}$, $n=3)$ and $10 \mu \mathrm{M}$ CTIBD-treated $(\boldsymbol{\square}, n=3) \mathrm{rSlo} / \mathrm{r} \beta 1$ coexpression channel. Each error bar indicates S.D. To obtain time-constant values, all current traces were fitted individually with the exponential standard function $\left[\mathrm{y}(\mathrm{t})=\mathrm{A}_{1} \exp \left(-\mathrm{t} / \tau_{1}\right)+\mathrm{C}\right]$ in the Clampfit program. Two-tailed paired $t$ test was used for statistical analysis $(* P$ value $<0.05$; $* * P$ value $<0.01)$.
Relaxation Effect of CTIBD on Rat Bladder Smooth Muscle Strips. Since it is well documented that the activation of the $\mathrm{BK}_{\mathrm{Ca}}$ channel relaxes the smooth muscle in the bladder, we investigated whether CTIBD exerted relaxation effects on excised bladder strips from rats (Fig. 9). Initially, $10 \mu \mathrm{M}$ ACh was applied to rat detrusor muscle strips, and the isometric tension was measured. ACh treatment caused the tension to rise dramatically. Immediately afterward, tension decreased and plateaued at half of the peak level. Pretreatment with CTIBD concentration-dependently reduced AChinduced peak contractions (Fig. 9A). Although 3 and $10 \mu \mathrm{M}$ CTIBD did not produce significant relaxation, significant relaxation by CTIBD was observed at higher concentrations: $42.1 \% \pm 21.1 \%$ at $30 \mu \mathrm{M}, 65.3 \% \pm 14.0 \%$ at $100 \mu \mathrm{M}$, and $81.4 \% \pm 10.2 \%$ at $300 \mu \mathrm{M}$ compared with controls (Fig. 9B). The $\mathrm{EC}_{50}$ value of CTIBD was determined as $28.0 \pm 5.0 \mu \mathrm{M}$.
A
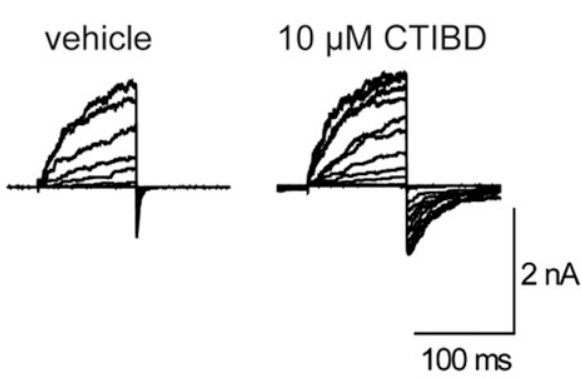

C

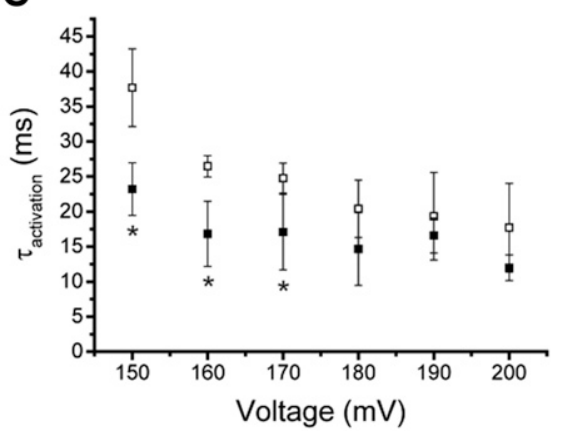

B

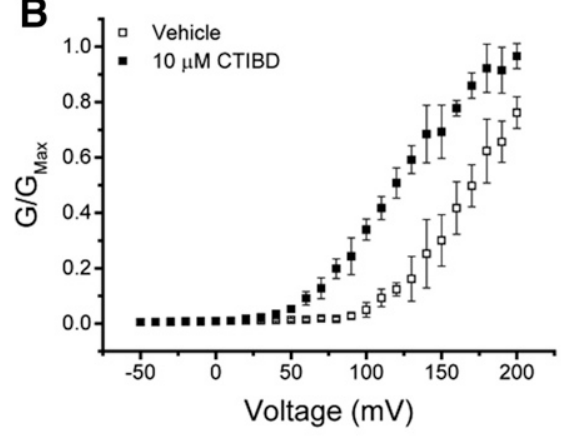

D

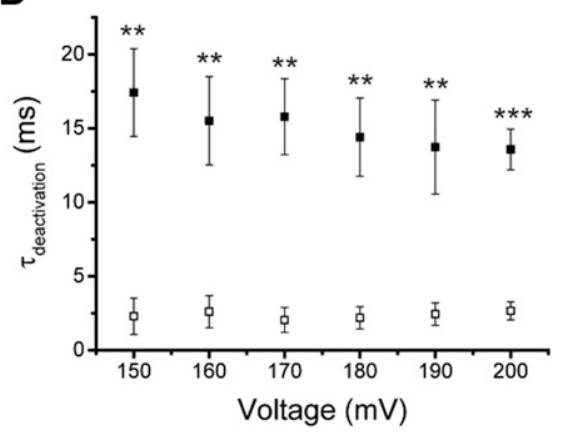

Fig. 8. Effects of $\beta 4$ subunits on CTIBD-induced activation of the $\mathrm{BK}_{\mathrm{Ca}}$ channel. Intracellular $\mathrm{Ca}^{2+}$ concentration was $3 \mu \mathrm{M}$. (A) Representative current traces of $\mathrm{rSlo} / \mathrm{r} \beta 4$ coexpression channel. Vehicle was DMSO $(0.1 \%)$. CTIBD $(10 \mu \mathrm{m})$ was applied to the extracellular side of the channel. The duration of the voltage pulses was 100 milliseconds. Currents were recorded at every voltage pulse, which were increased from -80 to $200 \mathrm{mV}$ in $10-\mathrm{mV}$ increments. The holding voltage was $-100 \mathrm{mV}$. Representative current traces at every $20 \mathrm{mV}$ from -80 to $200 \mathrm{mV}$ are shown. (B) Effects of CTIBD on the conductance-voltage relationship of $\mathrm{rSlo} / \mathrm{r} \beta 4$ coexpression channel. After initiation of voltage pulses, mean conductances were obtained from outward current values obtained between 40 and 60 milliseconds. All currents were normalized to the maximum current obtained with $10 \mu \mathrm{M}$ CTIBD. Vehicle $(\square, 0.1 \%$ DMSO, $n=4)$ and $10 \mu \mathrm{M}(\boldsymbol{\square}, n=4)$ CTIBD were applied to the extracellular side of the channel. (C) $\tau_{\text {activation }}$ of the vehicle-treated ( $\square, 0.1 \%$ DMSO, $n=4)$ and $10 \mu \mathrm{M}$ CTIBD-treated $(\mathbf{\square}, n=4) \mathrm{rSlo} / \mathrm{r} \beta 4$ coexpression channel. (D) $\tau_{\text {deactivation }}$ of the vehicletreated $(\square, 0.1 \%$ DMSO, $n=4)$ and $10 \mu \mathrm{M}$ CTIBDtreated $(\mathbf{\square}, n=4) \mathrm{rSlo} / \mathrm{r} \beta 4$ coexpression channel. Each error bar indicates S.D. To obtain timeconstant values, all current traces were fitted individually with the exponential standard function $\left[\mathrm{y}(\mathrm{t})=\mathrm{A}_{1} \exp \left(-\mathrm{t} / \tau_{1}\right)+\mathrm{C}\right]$ in the Clampfit program. Two-tailed paired $t$ test was used for statistical analysis ( $* * P$ value $<0.01 ; * * * P$ value $<0.001$ ). 
CTIBD did not show any relaxation effect on rat bladder strips at basal condition without ACh (Supplemental Fig. 6).

Effects of CTIBD on the Micturition Function of OAB Rats. To observe the therapeutic effects of CTIBD on micturition, CTIBD was injected intraperitoneally into an AAinduced rat model of OAB. Rats infused with normal saline showed three voiding contractions at regular intervals, whereas rats treated with $0.5 \% \mathrm{AA}$ showed hyperactive frequent voiding contractions (Fig. 10A, middle panel). Pretreatment of rats with $20 \mathrm{mg} / \mathrm{kg}$ CTIBD decreased the number of voiding contractions to basal levels (Fig. 10A, right panel). Thus, CTIBD restored the frequency of AA-induced voiding contractions to the basal state. During the in vivo cystometry experiments, basal pressure, maximum pressure of voiding contraction, intercontraction interval, and voiding volume were analyzed (Fig. 10B). CTIBD treatment did not significantly alter basal pressure or maximum pressure of voiding contraction. However, CTIBD treatment increased $0.5 \% \mathrm{AA}-$ induced significant decreases in the intercontraction interval (Fig. 10D) and voiding volume (Fig. 10E). These results indicate that CTIBD produces anti-OAB effects in rats, which are most likely caused by relaxation of bladder detrusor muscle.

\section{Discussion}

In this study, we aimed to identify new chemical activators of the $\mathrm{BK}_{\mathrm{Ca}}$ channel that contained novel skeletons. Initially, a chemical library containing 8364 unique compounds was screened using a cell-based fluorescence assay that we previously established (Lee et al., 2013). From the library, 25 compounds evoked a fluorescence that was at least 1.5-fold higher than vehicle (1\% DMSO) at 100 milliseconds (data not shown). A single compound, identified subsequently as 4-(4-phenyl)-3(trifluoromethyl)isoxazol-5-yl)benzene-1,3-diol (compound 1), was prominent in rapidly and robustly increasing fluorescence (Fig. 1). We then purchased 19 additional compounds containing a phenyl-isoxazolyl benzene skeleton for a structure-activity relationship (SAR) study.

Among the 20 compounds tested, nine compounds increased fluorescence significantly, with $P$ values $<0.05$ (Fig. 2; Supplemental Fig. 2). Three compounds were especially potent in the fluorescence assay. $\mathrm{EC}_{50}$ values were determined as $7.7 \pm 0.5 \mu \mathrm{M}$ for compound $1,3.9 \pm 0.6 \mu \mathrm{M}$ for compound 4 , and $9.4 \pm 1.7 \mu \mathrm{M}$ for compound 7 . Thus, compound 4 (CTIBD) was chosen for further study (Supplemental Fig. 3). Compound 4 (CTIBD) increased the fluorescence signal most rapidly and highly among all derivatives tested in a concentration-dependent manner (Fig. 3). Results from the SAR study suggest that $m$-dihydroxy and trifluoromethyl moieties are essential for activity as channel activators. Although compound 4, with a $p$-chloro substituent of (4-(4-(4-chlorophenyl)-3(trifluoromethyl)isoxazol-5-yl)benzene-1,3-diol), was most active, there is clearly room for further optimization of this class of compounds, and thus more extensive SAR studies would be of great value.

We validated the potentiating effects of CTIBD on $\mathrm{BK}_{\mathrm{Ca}}$ channel activity and investigated its mechanism of action. Application of CTIBD to the extracellular side of the channel reversibly and concentration-dependently potentiated macroscopic currents of the $\mathrm{BK}_{\mathrm{Ca}}$ channel (Fig. 4). The potentiation and depotentiation trajectories could be fitted with
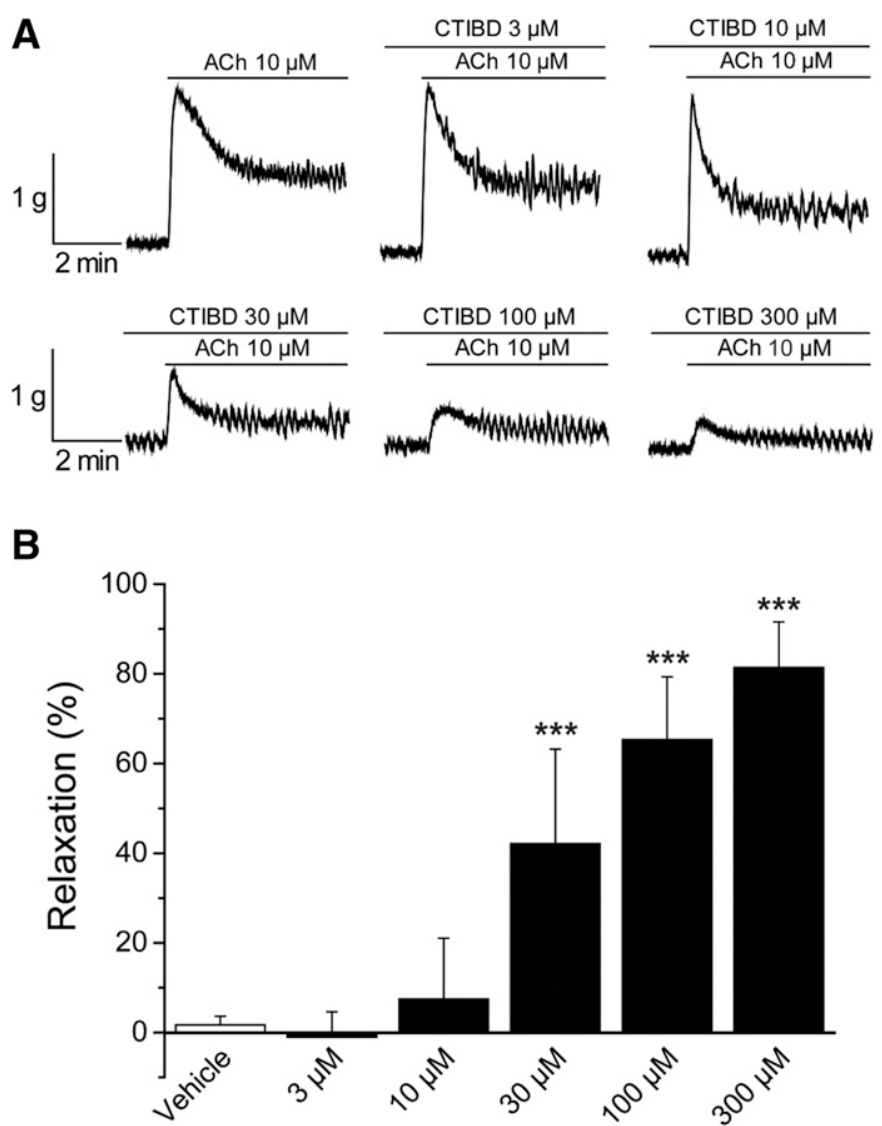

Fig. 9. Effect of CTIBD on ACh-induced contractions in isolated rat urinary bladder strips. Contractions were induced by ACh $(10 \mu \mathrm{M}) 30$ minutes after addition of CTIBD or control ( $0.1 \%$ DMSO). (A) Representative traces of the CTIBD-induced relaxation response. (B) Percentage relaxation, expressed as the decrease in ACh-induced contraction produced by CTIBD relative to the maximum ACh-induced contraction. Each error bar indicates S.D. One-way ANOVA followed by Dunn-Sidak post-test was used for statistical analysis $\left(n=8\right.$ or $9,{ }^{* * *} P$ value $<0.001$, compared with control)

double-exponential functions, indicating that the channel current comprised two different phases: an early fast phase and a late slow phase. One plausible explanation for this is that CTIBD simply has two different binding sites on the channel, each with distinct affinities: one site with high affinity and the other with lower affinity. Since the $\mathrm{BK}_{\mathrm{Ca}}$ channel is composed of four $\alpha$ subunits, four identical affinity sites should exist in a tetrameric holo-channel with 4-fold symmetry. Thus, it is also conceivable that the binding of CTIBD to a single site of high affinity may convert another site to a lower-affinity binding site. It will be intriguing to determine experimentally the stoichiometry of CTIBD binding to individual channel subunits and also to determine the binding site on the channel that is responsible for current potentiation.

Mechanistically, CTIBD affects both voltage-dependent activation and maximum conductance of the channel. CTIBD concentration-dependently shifted the $G-V$ relationship of the $\mathrm{BK}_{\mathrm{Ca}}$ channel progressively to a negative direction (Fig. 5). Based on extrapolation, the maximum shift of $V_{1 / 2}$ value was estimated as $-70.3 \mathrm{mV}$. CTIBD also increases the maximum channelconductance at a given voltage. It is reported that the open probability of the $\mathrm{BK}_{\mathrm{Ca}}$ channel does not reach unity even at extreme positive voltages (Sigg and Bezanilla, 1997; Ma 
A
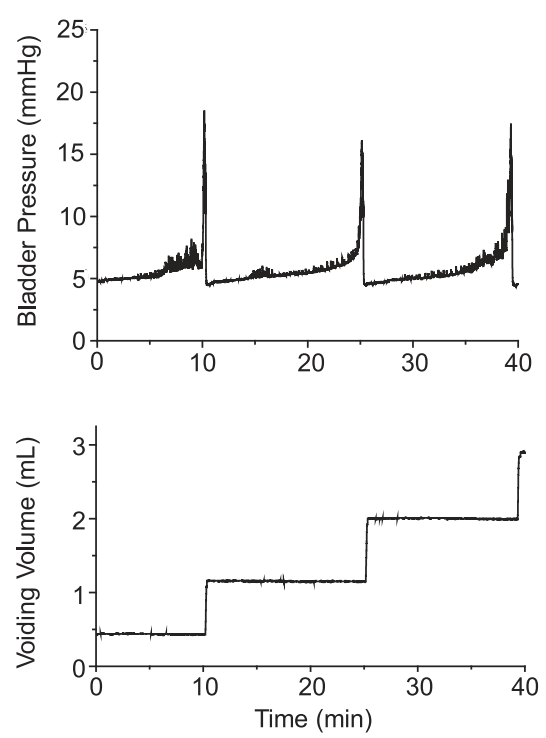

$0.5 \%$ Acetic Acid
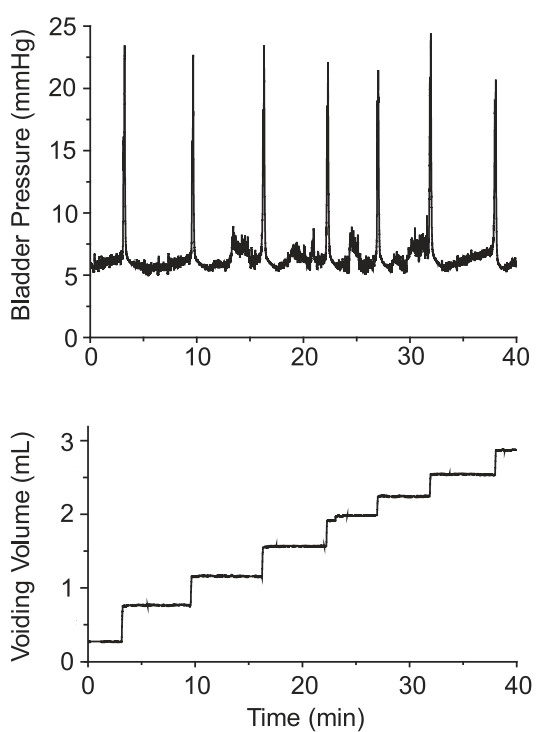

CTIBD $20 \mathrm{mg} / \mathrm{kg}$
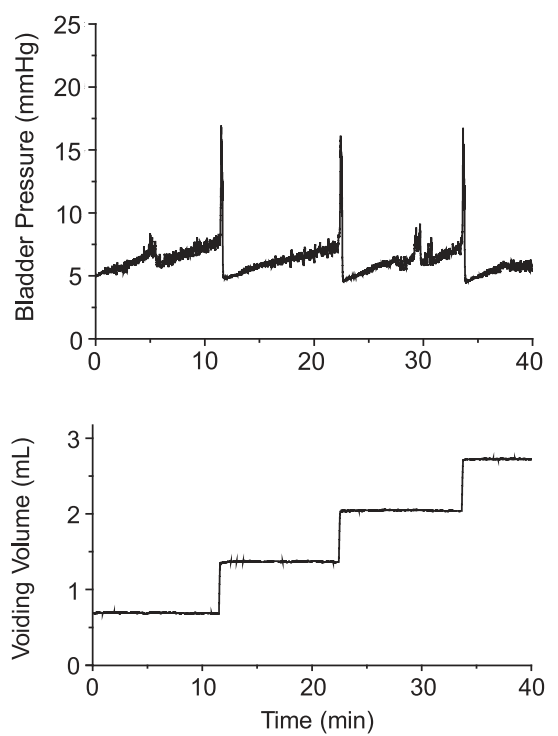

E

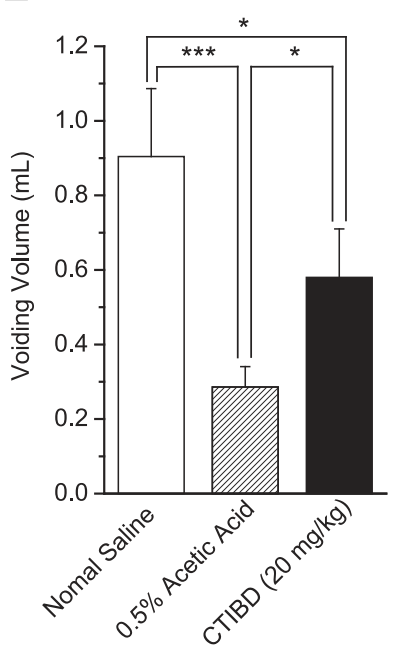

B

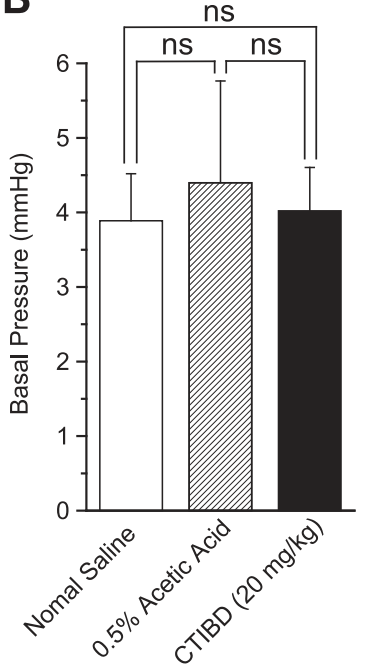

C

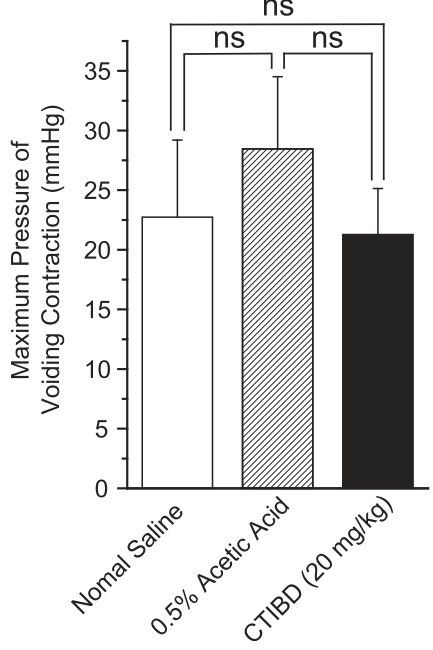

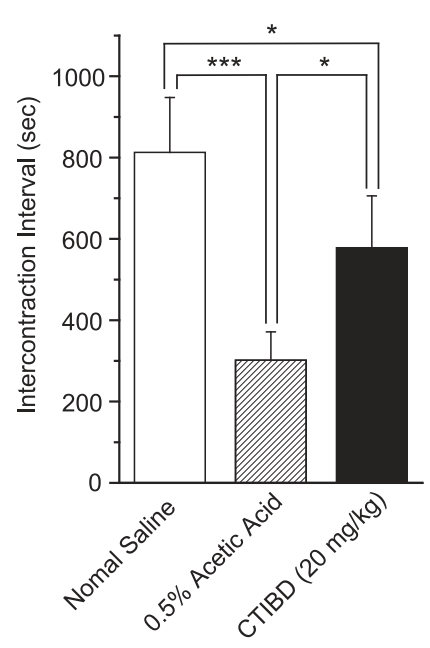

Fig. 10. In vivo cystometry. (A) Representative traces of cystometrogram data in rats treated with normal saline, $0.5 \%$ acetic acid (to induce bladder hyperactivity), and CTIBD. In CTIBD-treated rats, $20 \mathrm{mg} / \mathrm{kg}$ CTIBD was intraperitoneally injected after treatment with $0.5 \%$ acetic acid. Basal pressure (B), maximum pressure of voiding contraction (C), intercontraction interval (D), and voiding volume (E) of rats treated with normal saline, $0.5 \%$ acetic acid, or $20 \mathrm{mg} / \mathrm{kg}$ CTIBD. Acetic acid was intravesically infused until a voiding contraction occurred; 40 minutes later, CTIBD was administered intraperitoneally, and micturition patterns were recorded for 90 minutes. Each error bar indicates S.D. One-way ANOVA followed by Tukey's post-test was used for statistical analysis $\left(n=4,{ }^{*} P\right.$ value $<0.05$; *** $P$ value $<0.001$, ns is abbreviation of not significant).

et al., 2006). It will be intriguing to reveal in future research the mechanism of how the binding of CTIBD increases the maximum open probability and thus the maximum conductance of the $\mathrm{BK}_{\mathrm{Ca}}$ channel. Kinetically, CTIBD potentiated the activity of the $\mathrm{BK}_{\mathrm{Ca}}$ channel by dramatically slowing channel closing without significantly affecting the activation rate. At $10 \mu \mathrm{M}$ CTIBD, the closing rate of the channel was slowed by 11.6-fold at $160 \mathrm{mV}$. It is likely that CTIBD binds to the open conformation of the channel more tightly, thus stabilizing the open state of the channel and preventing the channel from closing.

Since the functional characteristics are altered by auxiliary $\beta$ subunits, the effects of $\beta$ subunits on CTIBD-induced $\mathrm{BK}_{\mathrm{Ca}}$ channel activation were studied. Two main $\beta$ subunits, $\beta 1$ and $\beta 4$ subunits, were expressed together with $\alpha$ (or Slo). It is worth mentioning that these two $\beta$ subunits are known to express predominantly in the bladder (Poulsen et al., 2009; Petkov, 2014). CTIBD shifted the $G-V$ curve of both $\mathrm{rSlo} / \mathrm{r} \beta 1$ and $\mathrm{rSlo} / \mathrm{r} \beta 4$ channels to negative direction (Figs. 7 and 8 ). Whereas $10 \mu \mathrm{M}$ CTIBD shifted the $V_{1 / 2}$ value of $\mathrm{rSlo} / \mathrm{r} \beta 1$ approximately $-16 \mathrm{mV}$, the same concentration of CTIBD shifted the $V_{1 / 2}$ of rSlo/r $\beta 4$ channel as much as $-40 \mathrm{mV}$. Thus, the potentiation of $\mathrm{BK}_{\mathrm{Ca}}$ channel by CTIBD was decreased by coexpression of both $\beta 1$ and $\beta 4$ subunits, but the reduced activation was more significant for $\beta 1$ than $\beta 4$. The expression of $\beta$ subunits also differentially affected the gating kinetics of CTIBD-induced $\mathrm{BK}_{\mathrm{Ca}}$ channel activation and deactivation. CTIBD activates both $\mathrm{rSlo} / \mathrm{r} \beta 1$ and $\mathrm{rSlo} / \mathrm{r} \beta 4$ channels mainly by slowing down the channel closure. A similar kinetic effect of CTIBD was also observed for the homomeric rSlo channel but 
was more significant compared to $\mathrm{rSlo} / \mathrm{r} \beta 1$ and $\mathrm{rSlo} / \mathrm{r} \beta 4$ coexpressed channels.

The $\mathrm{BK}_{\mathrm{Ca}}$ channel plays an important role in the contraction of UBSM by controlling the resting membrane potential and repolarization phase. Thus, we tested the effect of CTIBD on the relaxation of excised rat UBSM strips. As expected, pretreatment with CTIBD concentration-dependently inhibited ACh-induced contraction of rat UBSM strips at $30 \mu \mathrm{M}$ or higher concentrations. At the highest concentration of $300 \mu \mathrm{M}$, CTIBD inhibited ACh-induced contraction by $81.4 \%$ compared with the negative control. These results indicate that CTIBD relaxes UBSM. We then tested the efficacy of CTIBD on micturition in a rat model of AA-evoked $\mathrm{OAB}$. Acetic acids enhance sensitivity of neuronal activity of bladder smooth muscle cells and cause OAB in a rat model (Mitobe et al., 2008; Choudhary et al., 2015). Using in vivo cystometry, intraperitoneal injection of CTIBD $(20 \mathrm{mg} / \mathrm{kg})$ relaxed AA-induced frequent voiding contraction significantly. It is worth noting and encouraging that other parameters of bladder functions, such as the basal intravesical pressure and the maximum pressure of voiding contraction, were not significantly affected by CTIBD treatment.

In summary, a series of new $\mathrm{BK}_{\mathrm{Ca}}$ channel activators containing a 4-phenyl-isoxazol-5-yl benzene skeleton were identified, and one compound (CTIBD) was characterized as a novel potent activator of the channel. CTIBD potentiated the activity of the channel by directly binding to the channel and stabilizing its open conformation. In rats, CTIBD effectively relaxes UBSM ex vivo and bladder hyperactivity in vivo. Taken together, these results indicate that CTIBD and its derivatives that target the bladder $\mathrm{BK}_{\mathrm{Ca}}$ channel can be considered as strong new candidates for $\mathrm{OAB}$ therapeutics.

\section{Acknowledgments}

The chemical library used in this study was kindly provided by the Korea Chemical Bank (www.chembank.org) of the Korea Research Institute of Chemical Technology.

\section{Authorship Contributions}

Participated in research design: N. Lee, Park.

Conducted experiments: N. Lee, Lim, K.-S. Lee, Shin, S. W. Lee, Kang.

Contributed new reagents or analytic tools: H. S. Pagire, S. H. Pagire, Ahn.

Performed data analysis: N. Lee, Lim, K.-S. Lee, Shin, S. W. Lee, Kang, Park.

Wrote or contributed to the writing of the manuscript: N. Lee, Ahn, S. W. Lee, Kang, Park.

\section{References}

Abrams P and Andersson KE (2007) Muscarinic receptor antagonists for overactive bladder. BJU Int 100:987-1006.

Barrett JN, Magleby KL, and Pallotta BS (1982) Properties of single calciumactivated potassium channels in cultured rat muscle. J Physiol 331:211-230.

Bo XN and Burnstock G (1990) The effects of Bay K 8644 and nifedipine on the responses of rat urinary bladder to electrical field stimulation, beta,gammamethylene ATP and acetylcholine. Br J Pharmacol 101:494-498.

Cerruto MA, Asimakopoulos AD, Artibani W, Del Popolo G, La Martina M, Carone R, and Finazzi-Agrò E (2012) Insight into new potential targets for the treatment of overactive bladder and detrusor overactivity. Urol Int 89:1-8.

Choudhary M, van Asselt E, van Mastrigt R, and Clavica F (2015) Neurophysiological modeling of bladder afferent activity in the rat overactive bladder model. $J$ Physio Sci 65:329-338.

Cui J, Yang H, and Lee US (2009) Molecular mechanisms of BK channel activation. Cell Mol Life Sci 66:852-875.
Du W, Bautista JF, Yang H, Diez-Sampedro A, You S-A, Wang L, Kotagal P, Lüders HO, Shi J, Cui J, et al. (2005) Calcium-sensitive potassium channelopathy in human epilepsy and paroxysmal movement disorder. Nat Genet 37:733-738.

Eglen RM, Choppin A, Dillon MP, and Hegde S (1999) Muscarinic receptor ligands and their therapeutic potential. Curr Opin Chem Biol 3:426-432.

Gribkoff VK, Starrett JE Jr, and Dworetzky SI (2001) Maxi-K potassium channels: form, function, and modulation of a class of endogenous regulators of intracellular calcium. Neuroscientist 7:166-177.

Ha TS, Lim HH, Lee GE, Kim Y-C, and Park C-S (2006) Electrophysiological characterization of benzofuroindole-induced potentiation of large-conductance $\mathrm{Ca}^{2+}$. activated $\mathrm{K}^{+}$channels. Mol Pharmacol 69:1007-1014.

Hegde SS and Eglen RM (1999) Muscarinic receptor subtypes modulating smooth muscle contractility in the urinary bladder. Life Sci 64:419-428.

Hristov KL, Chen M, Kellett WF, Rovner ES, and Petkov GV (2011) Largeconductance voltage- and $\mathrm{Ca}^{2+}$-activated $\mathrm{K}^{+}$channels regulate human detrusor smooth muscle function. Am J Physiol Cell Physiol 301:C903-C912.

Kay GG and Granville LJ (2005) Antimuscarinic agents: implications and concerns in the management of overactive bladder in the elderly. Clin Ther 27:127-138.

Layne JJ, Nausch B, Olesen S-P, and Nelson MT (2010) BK channel activation by NS11021 decreases excitability and contractility of urinary bladder smooth muscle. Am J Physiol Regul Integr Comp Physiol 298:R378-R384.

Lee B-C, Kim H-J, Park SH, Phuong TTT, Kang TM, and Park C-S (2013) Development of cell-based assay system that utilizes a hyperactive channel mutant for high-throughput screening of $\mathrm{BK}_{\mathrm{Ca}}$ channel modulators. J Biotechnol 167: 41-46.

Lee S, Chae MR, Lee B-C, Kim Y-C, Choi JS, Lee SW, Cheong JH, and Park C-S (2016) Urinary bladder-relaxant effect of kurarinone depending on potentiation of large-donductance $\mathrm{Ca}^{2+}$-activated $\mathrm{K}^{+}$channels. Mol Pharmacol 90 (2):140-150.

Ma Z, Lou XJ, and Horrigan FT (2006) Role of charged residues in the S1-S4 voltage sensor of BK channels. J Gen Physiol 127:309-328.

Marty A (1981) Ca-dependent $\mathrm{K}$ channels with large unitary conductance in chromaffin cell membranes. Nature 291:497-500.

Meredith AL, Wiler SW, Miller BH, Takahashi JS, Fodor AA, Ruby NF, and Aldrich RW (2006) BK calcium-activated potassium channels regulate circadian behavioral rhythms and pacemaker output. Nat Neurosci 9:1041-1049.

Mitobe M, Inoue H, Westfall TD, Higashiyama H, Mizuyachi K, Kushida H, and Kinoshita M (2008) A new method for producing urinary bladder hyperactivity using a non-invasive transient intravesical infusion of acetic acid in conscious rats. $J$ Pharmacol Toxicol Methods 57:188-193.

Orio P, Rojas P, Ferreira G, and Latorre R (2002) New disguises for an old channel: MaxiK channel $\beta$-subunits. News Physiol Sci 17:156-161.

Patton C, Thompson S, and Epel D (2004) Some precautions in using chelators to buffer metals in biological solutions. Cell Calcium 35:427-431.

Petkov GV (2014) Central role of the BK channel in urinary bladder smooth muscle physiology and pathophysiology. Am J Physiol Regul Integr Comp Physiol 307: R571-R584.

Poulsen AN, Wulf H, Hay-Schmidt A, Jansen-Olesen I, Olesen J, and Klaerke DA (2009) Differential expression of BK channel isoforms and beta-subunits in rat neuro-vascular tissues. Biochim Biophys Acta 1788:380-389.

Salkoff L, Butler A, Ferreira G, Santi C, and Wei A (2006) High-conductance potassium channels of the SLO family. Nat Rev Neurosci 7:921-931.

Sanchez M and McManus OB (1996) Paxilline inhibition of the alpha-subunit of the high-conductance calcium-activated potassium channel. Neuropharmacology 35: 963-968

Sigg D and Bezanilla F (1997) Total charge movement per channel. The relation between gating charge displacement and the voltage sensitivity of activation. $J$ Gen Physiol 109:27-39.

Sprossmann F, Pankert P, Sausbier U, Wirth A, Zhou XB, Madlung J, Zhao H, Bucurenciu I, Jakob A, Lamkemeyer T, et al. (2009) Inducible knockout mutagenesis reveals compensatory mechanisms elicited by constitutive BK channel deficiency in overactive murine bladder. FEBS $J$ 276:1680-1697.

Stewart WF, Van Rooyen JB, Cundiff GW, Abrams P, Herzog AR, Corey R, Hunt TL, and Wein AJ (2003) Prevalence and burden of overactive bladder in the United States. World J Urol 20:327-336.

Wang X, Inukai T, Greer MA, and Greer SE (1994) Evidence that $\mathrm{Ca}^{2+}$-activated $\mathrm{K}^{+}$ channels participate in the regulation of pituitary prolactin secretion. Brain Res 662:83-87.

Wang Z-W (2008) Regulation of synaptic transmission by presynaptic CaMKII and BK channels. Mol Neurobiol 38:153-166.

Werner ME, Knorn A-M, Meredith AL, Aldrich RW, and Nelson MT (2007) Frequency encoding of cholinergic- and purinergic-mediated signaling to mouse urinary bladder smooth muscle: modulation by BK channels. Am J Physiol Regul Integr Comp Physiol 292:R616-R624.

Werner ME, Zvara P, Meredith AL, Aldrich RW, and Nelson MT (2005) Erectile dysfunction in mice lacking the large-conductance calcium-activated potassium (BK) channel. J Physiol 567:545-556.

Wu RS and Marx SO (2010) The BK potassium channel in the vascular smooth muscle and kidney: $\alpha$ - and $\beta$-subunits. Kidney Int 78:963-974.

Yang H, Zhang G, and Cui J (2015) BK channels: multiple sensors, one activation gate. Front Physiol 6:29.

Address correspondence to: Chul-Seung Park, School of Life Sciences, Center for AI-applied High Efficiency Drug Discovery, and Integrated Institute of Biomedical Research, Gwangju Institute of Science and Technology (GIST), 123, Cheomdangwagi-ro, Buk-gu, Gwangju, Republic of Korea. E-mail: cspark@gist.ac.kr 